Article

\title{
Sustainable, Full-Scope Nuclear Fission Energy at Planetary Scale
}

\section{Robert Petroski $^{1, *}$ and Lowell Wood ${ }^{2}$}

1 Nuclear Innovation Engineer, TerraPower LLC, 330 120th Avenue NE, Suite 100, Bellevue, WA 98005, USA

2 Hoover Institution, Stanford University, Stanford, CA 94305, USA;

E-Mail: lowellwood@comcast.net

* Author to whom correspondence should be addressed; E-Mail: rpetroski@terrapower.com; Tel.: +1-510-517-8106; Fax: +1-425-467-2350.

Received: 25 July 2012; in revised form: 1 November 2012 / Accepted: 7 November 2012 /

Published: 13 November 2012

\begin{abstract}
A nuclear fission-based energy system is described that is capable of supplying the energy needs of all of human civilization for a full range of human energy use scenarios, including both very high rates of energy use and strikingly-large amounts of total energy-utilized. To achieve such "planetary scale sustainability", this nuclear energy system integrates three nascent technologies: uranium extraction from seawater, manifestly safe breeder reactors, and deep borehole disposal of nuclear waste. In addition to these technological components, it also possesses the sociopolitical quality of manifest safety, which involves engineering to a very high degree of safety in a straightforward manner, while concurrently making the safety characteristics of the resulting nuclear systems continually manifest to society as a whole. Near-term aspects of this nuclear system are outlined, and representative parameters given for a system of global scale capable of supplying energy to a planetary population of 10 billion people at a per capita level enjoyed by contemporary Americans, i.e., of a type which might be seen a half-century hence. In addition to being sustainable from a resource standpoint, the described nuclear system is also sustainable with respect to environmental and human health impacts, including those resulting from severe accidents.
\end{abstract}


Keywords: nuclear fission energy; breeder reactor; traveling wave reactor; manifest safety; seawater uranium extraction; deep borehole nuclear waste disposal; nuclear process heat; nuclear transportation

\section{Introduction}

Is energy derived from processes involving nuclear fission of isotopes of actinide elements - simply 'nuclear energy', in the following discussion-sustainable for purposes of powering human civilization into the indefinite future?

Energy obtained from classic renewable sources is widely if perhaps somewhat uncritically agreed to be sustainable, while energy from fossil fuels is generally deemed to not be sustainable. No similar consensus exists for nuclear energy, and the assessment likely depends on one's criteria for sustainability and which characteristics of nuclear energy are weighed most heavily in the judgment. For example, proponents of nuclear energy highlight its asymptotic lack of greenhouse gas emissions and its already-demonstrated capability to 'work' at full scale of the present day, while critics point to issues associated with wastes from the nuclear fission process, risks of diversion of fissile materials to creation of nuclear weapons, and the possibility of severe accidents involving large-scale releases of radioactive materials into the biosphere.

In order to become generally accepted as a sustainable source of energy, nuclear energy must address these pertinent, substantive critiques. This paper sketches a portrait of a nuclear energy system which can resolve these criticisms in largely-technological manners, while greatly extending the energy extractable from known uranium resources, thereby proffering fully environmentally and socially sustainable energy supply over extremely long timescales.

This full-scale, indefinitely-durable nuclear energy system is based on three technologies currently under development: uranium recovery from seawater, manifestly safe nuclear breeder reactors, and deep-borehole disposal of nuclear waste streams.

Appropriately integrated, these technologies have the potential to make nuclear fission-derived energy functionally similar to conventional renewable energy from a sustainability perspective, while enabling it - perhaps operating in concert with renewable technologies - to supply mankind's entire global energy requirements for extremely long timescales, moreover at remarkably-large power levels and with vanishingly-small social and environmental costs and risks.

The purpose of describing such a planetary-scale nuclear energy system is not to offer a prescription or even a recommendation for future energy policy, but instead simply to explore from a technical perspective nuclear energy's ability to meet human energy demands. Energy policy is an immensely complex subject influenced by a multitude of social and economic factors with strong regional variations. Information about the current world energy supply and future projections can be found in [1,2]. Information pertaining specifically to present-day nuclear generation can be found in [3]. 


\section{The Scope of Nuclear Sustainability}

The goal of the contemplated nuclear energy system is to be fully sustainable along three axes: resource availability, environmental and social impacts, and range of applicability. What is encompassed within these three dimensions is described in subsections 2.1 through 2.3; together they concretely define what we mean by "nuclear sustainability."

\subsection{Resource Availability}

While renewable energy sources such as wind, solar, and hydro will last as long as the sun shines and the rain falls, chemical fuel sources are finite, with known resources estimated to last of the order of decades (e.g., for oil) or centuries (e.g., for coal and natural gas) at current usage rates. Such chemical energy resources likely will never truly "run out," but instead will come to cost so much to bring-to-market that they will be economically-interesting feedstream-sources only for ever-more-highly-specialized applications. Nuclear resources (uranium and thorium in the fission context, and deuterium and lithium in the fusion context) are also finite in the sense that there is a fixed total quantity of each of them on the planet Earth. However, the energy content of these nuclear energy resources - 1-10 million times that of chemical energy ones, on a pound-for-pound basis - means that this "finite" supply may last for an indefinitely long interval from the perspective of terrestrial human energy use, when pertinent scales are quantitatively considered.

How much total energy is needed from an energy source before it can be considered to last indefinitely long and therefore be "effectively limitless"? Any response to this question necessarily has a somewhat subjective character, and also is dependent on how one projects future energy demand. We therefore consider a range of scenarios spanning two extremes: one in which global energy use stabilizes at levels capable of comfortably sustaining a population of 10 billion people (e.g., at the level presently enjoyed by Americans), and another in which energy supply and use continues to steadily-i.e., exponentially-increase indefinitely into the future.

These two bounding scenarios are illustrated as the two bold curves in Figure 1, with intermediate scenarios occupying the parameter space between them. It seems worthwhile to consider such a range of scenarios because of the unpredictability of mankind's future use of energy. The history of the past century-during which the time-averaged pace of technological advance was comparatively leisurely, relative to the present level-makes abundantly clear that it is foolish to attempt to predict even one century forward in time what human society will look like, including what new technologies, energy sources, and energy uses may then exist.

In Figure 1, the starting point for both bounding scenarios is one that corresponds to a global society comprised of 10 billion humans, each with per capita primary energy consumption equal to that of the present day United States: $\sim 330 \mathrm{GJ} / \mathrm{y}$, or $\sim 10 \mathrm{~kW}$ of time-average power; this figure is for energy from primary sources, and therefore includes energy lost as heat, e.g., during electricity generation, operation of vehicular heat-engines, etc. [4]. This corresponds to an annual consumption of $3.3 \times 10^{21}$ $\mathrm{J} / \mathrm{y}$, equivalent to a time-average global power of about $1.0 \times 10^{14} \mathrm{~W}$, or $100 \mathbf{T W}$, about six times higher than current energy use levels - reflecting the fact that $\sim 80 \%$ of humanity currently lives in the Developing World and that the planetary population is UN-estimated in its 'central case' to grow by 
$\sim 50 \%$ before it eventually stabilizes. This starting point is also used as the reference point in later calculations of a global nuclear energy system. For simplicity, the difference between primary energy supplied and energy consumed in end uses (i.e., the efficiencies of different energy uses) is neglected; this has only a comparatively modest effect on the order-of-magnitude values which we consider.

Figure 1. Range of scenarios considered and ability of different energy levels to sustain them.

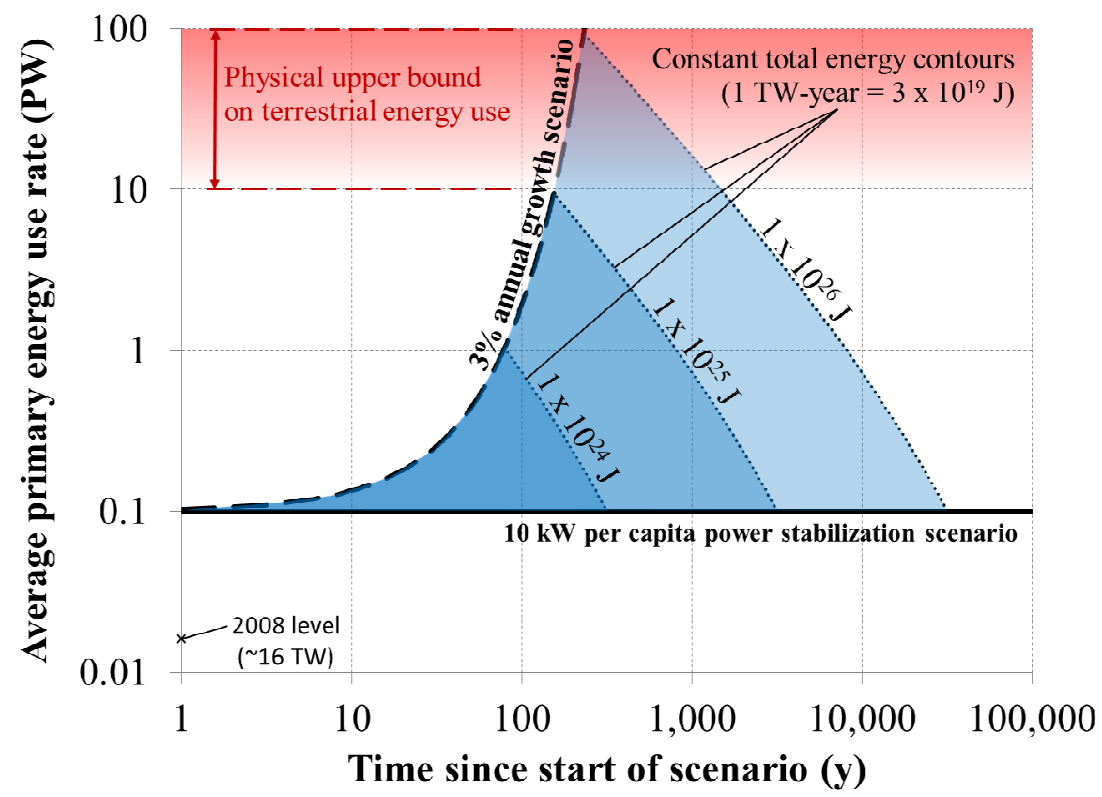

From this starting point-which may be attained even early in the second half of the present century - the lower bound in Figure 1 represents a scenario in which energy use stabilizes at the aforementioned $100 \mathrm{TW}$ level, just adequate to provide every human with contemporary U.S.A. levels of power-production. This is plausible given that energy use in some extensively developed countries is currently on the decline, as populations remain stable and extant energy applications become more efficient. In contrast, the upper bound in Figure 1 illustrates a scenario in which global energy use grows steadily at a rate of 3\% per year, continuing the long-term global trend from the 20th century. The area between these two bounds includes all scenarios that have intermediate or variable growth rates between none and the singularly-great one of the past century.

Also shown in Figure 1 are contour lines corresponding to different amounts of total energy use. The shaded regions contained by these contour lines indicate positions on the time-energy use "map" that can be attained while using a specified amount of energy. For example, with a total energy usage of $1.0 \times 10^{24} \mathrm{~J}$, one may sustain the $100 \mathrm{TW}$ stabilization scenario for a duration of approximately 300 years, or one may grow total power consumption in the growth scenario to $1.0 \times 10^{15} \mathrm{~W}-1000$ $\mathrm{TW}$, a factor of 10 higher than at the outset - over a shorter time-interval, roughly 80 years. One may also reach all the other points shown within the $1.0 \times 10^{24} \mathrm{~J}$ contour via various power-time trajectories, representing different ways of trading off power growth and energy duration. These contours are not intended to represent sharp boundaries, since they would inevitably become blurred as transitions between different energy technologies take place. For example, with $1.0 \times 10^{24} \mathrm{~J}$ of energy available from any particular resource, it seems unlikely that resource would be used to 
supply 100 TW for 300 years and zero power thereafter; instead, it is more likely that use of that resource would be gradually phased out and slowly replaced by a different source of energy.

Within the map laid out in Figure 1, there are no firm landmarks delineating whether any given total amount of energy is definitively "sustainable" or not. Instead, with increasing total energy availability, more of the map becomes accessible, and more possible scenarios can be considered within that total amount of energy. To proceed with a reasonable upper-bounding figure, the contour corresponding to $\mathbf{1 . 0} \times \mathbf{1 0}^{\mathbf{2 5}} \mathbf{J}$ of total energy production is proposed here as being fully sustainable for all scenarios of interest from present-day perspectives.

In the scenario corresponding to stabilization of total global power production at a $100 \mathrm{TW}$ level, $1.0 \times 10^{25} \mathrm{~J}$ is capable of sustaining all energy human needs for the order of three millennia, roughly the same duration as all of recorded history, which spans approximately five millennia. Such an extended time horizon leaves an immense amount of time (and energy-undergirded technological development) for future generations to realize additional sources of energy, since the time required for a wholesale shift in energy sourcing has historically ranged from just a few decades to as long as a century, during the course of major human industrialization over the past half-millennium. An "ultimate" energy source extended beyond this time-interval might include full-scale renewable technologies of already-conventional natures, energy from nuclear fusion, or perhaps more exotic approaches such as solar energy harvesting in space.

Meanwhile, following the $3 \%$ annual growth scenario, $1.0 \times 10^{25} \mathrm{~J}$ is capable of propelling mankind to energy use rates on the order of $1.0 \times 10^{16} \mathrm{~W}$ or $\mathbf{1 0} \mathbf{P W}$, two orders of magnitude greater than the 100 TW steady-state scenario and a factor of six hundred greater than the present global energy supply, over a time-interval of less than two centuries. Such a vast rate of energy use would allow mankind access to currently unprecedented capabilities, such as information processing on incredibly massive scales, control of global environmental phenomena such as weather-and-climate, the ability to engineer ecosystems on mesoscales (e.g., to convert the Earth's major deserts to arable land), and the ability to launch enormous mass-fluxes into space.

As indicated by the dashed horizontal line in Figure 1, a level of energy use exceeding $10 \mathrm{PW}$ is likely bounding for a fundamental physical reason: it begins to approach-from-below the total incoming energy-rate the Earth receives from the Sun $(\sim 170 \mathrm{PW})$. For terrestrially-sourced energy such as fossil fuels, nuclear fission/fusion, as well as geothermal energy, adding energy significantly beyond this scale to the energy budget of the Earth's surface would require a corresponding major increase in the Earth's surface average temperature (or its concatenated spatially-, time- and spectrally-averaged emissivity) in order to radiate this 'extra' energy-rate into space, or novel means to sink remarkably immense quantities of energy into the oceans or back into the solid Earth. For non-geothermal renewable energy, the power received from the Sun is a hard limit on how much can be harvested, since these forms of energy (wind, solar, hydro) are ultimately derived from the Sun (neglecting the small-scale exception of tidal energy). Expanding mankind's energy supply far beyond this level would require extraterrestrial energy production (and use), such as collecting solar energy in space. In such a situation mankind will no longer be solely dependent on terrestrially sourced energy, and standard terrestrial notions of resource sustainability would no longer apply. (This situation would correspond to mankind's transition from a Kardashev Type I civilization (one using as much energy as available on a planet) to a Type II civilization (one using as much energy as available from a star) [5].) 
In addition to these two scenarios with either an extremely long duration or an extremely high energy use rate, an energy resource supplying a total of $1.0 \times 10^{25} \mathrm{~J}$ also allows a full range of intermediate scenarios which are also highly appealing from a sustainability standpoint. For example, Figure 1 shows that it would be possible to sustain gradual growth to ten times the initial level of energy utilization (to a $1 \mathrm{PW}$ total power level) over the course of approximately 1000 years, combining a large absolute growth in energy use with a seemingly far more-than-sufficient duration within which to transition to use of "ultimate" energy sources.

To give a sense of scale for this $1 \times 10^{25} \mathrm{~J}$ figure, the total energy obtainable from technically recoverable (without regard to cost) conventional oil reserves, both proven and speculative, is estimated to be about $1.4 \times 10^{22} \mathrm{~J}$ (corresponding to 2.3 trillion barrels, based on United States Geological Survey mean estimates [6]), i.e., far smaller than the requirement for full-scope sustainability of a terrestrial civilization just described. Including nonconventional oil reserves (shale oil and tar sands) can increase this to about $5 \times 10^{22} \mathrm{~J}$ (assuming conventional resources make up 30\% of total oil reserves [7]). Adding reasonably-projected recoverable inventories of coal (948 billion short tons [8]) and natural gas (2.3 trillion barrels of oil equivalent of conventional resources [6] and assuming an equal amount of unconventional resources such as shale gas) brings the total to about $\mathbf{1 . 0} \times \mathbf{1 0}^{\mathbf{2 3}} \mathbf{J}$, still 2 orders of magnitude too small. If one further assumes that improved technology allows us to recover twice as much fossil fuel as these quoted figures, as well as harvest more speculative under-ocean methane clathrates (containing approximately $2500 \mathrm{Gt}$ of carbon [9]), the total energy content of fossil fuels would be raised to approximately $4 \times 10^{23} \mathrm{~J}$-with a substantial uncertainty band-narrowing the gap to 'only' $\sim 25 \mathrm{X}$. All fossil fuels aggregated are therefore innately insufficient for enabling the full range of planetary-scale sustainable civilization-powering options outlined above, in total energy terms alone, pivotal though their usage may be in the very near-term.

\subsection{Environmental and Social Impacts}

For any energy technology to be sustainable, it needs to have eminently tolerable and readily mitigated impacts on the natural environment as well as human health. For all such technologies, this includes avoiding habitat destruction and other land-use costs and minimizing creation and/or sequestering undesirable byproducts of energy-generation and -utilization, specifically including the limiting of net undesired emissions over energy system lifecycles. For nuclear energy systems in particular, three specific impact-based criteria must be applied because of their unique radiological characteristics, pertaining to ensuring safe operations of nuclear facilities, aptly disposing of radioactive wastes arising from nuclear processes, and precluding diversion of fissile materials to creation of nuclear weapons.

For nuclear energy, the possibility of accidents involving large-scale releases of radioactive material is arguably the most important issue concerning its sustainability, due to the potentially wide-area and extended duration characteristics of such events: populations of significant size may thereby receive radiation doses that may induce difficult-to-quantify health effects, and large areas can become contaminated with radioactive material, some of which may be only quite slow to decay. Even if the health effects of most such events may be so small as to be technically unmeasurable, or even zero-as indeed recent research results suggest is likely to be the general case [10] - the psychological impact 
can nevertheless be remarkably great, due to the statistical — and thus innately uncertain — nature of radiological hazards and the presently-great challenge of medically addressing radiation injuries in definitive manners.

How safe is "safe enough" when it comes to potentially devastating nuclear accidents? For nuclear energy to be considered safe enough to be used in a sustainable fashion, it may be necessary for such accidents to become truly incredible events, once-per-several-decades or once-per-century events that occur anywhere on the entire planet perhaps once in the lifetime of an average person, even in scenarios where human civilization derives most of its energy from nuclear sources. This may be necessary for the public to view nuclear energy as having net-acceptable risk, similarly to the way in which air travel is viewed as "safe enough" due to its exceptional safety record: it's currently at least an order-of-magnitude safer per passenger-mile to travel by commercial air than by car, although airplane accidents are innately larger in scale and much more fatality-intensive, so the traveling public looks at the safety statistics and elects to fly in ever-greater numbers. (Curiously enough, nuclear generation of electricity has been extensively documented in (mostly European) studies [11,12] to involve 10-to-100-fold lower loss-of-life per kW-h of energy generated than other large-scale sources of electricity, but enjoys considerably lower public acceptance, perhaps due in part to the acute life-risks of non-nuclear electricity being borne mostly by small, self-selected sub-populations (e.g., coal miners; sub-populations living immediately downstream of large dams) while the corresponding benefits are enjoyed by the public-at-large - in distinct contrast to the risks-and-benefits of nuclear electricity being more uniformly distributed.)

In the "adequately-energized global society" scenario introduced earlier which might be mostly realized a half-century hence, global energy use is of the order $100 \mathrm{TW}$, which corresponds to roughly 30,000 nuclear reactors each generating a few gigawatts. For such a fleet to experience publically-perceptible accidents as extraordinarily rare events, each reactor would need a probability of significant release of radioactive materials to the biosphere no greater than $\mathbf{1} \times \mathbf{1 0}^{\mathbf{- 6}}$ per year of reactor operation. This probability-rate would have to continue to decrease as the number of reactors around the world would increase thereafter, in order to maintain a comparable overall frequency of significant releases of radioactive materials.

In addition to achieving this high degree of reactor integrity against radioactive release, a sustainable nuclear energy system must address another source of potential releases: waste-streams from nuclear energy-generating processes. A suitable disposal technology must be demonstrated as being able to reliably, permanently and irretrievably dispose of nuclear waste, where "permanent" refers to timescales well in excess of a millennium - and preferably far longer. For such a disposal technology to be sustainable, it must be capable of being scaled to sustainably support a global fleet of $\sim 30,000$ GWe-scale nuclear reactors without major environment impact.

Finally, a sustainable nuclear energy system must be able to limit the potential diversion of fissile nuclear materials into nuclear weapons-creating activities. This means that nuclear sustainability inevitably has a policy component to it as well, since policy solutions are likely the single most useful ones in discouraging the pursuit of nuclear weaponry and thus in diminishing the impetus to challenge barriers to diversion of fissile materials - although intelligently-exercised technology can provide long levers for apt ad hoc anti-diversion policy, directed against both covert and state-sanctioned diversions. Such barriers thereby can be both simpler to create and operate and more reliable in operation. 
Indeed, while political will to prevent diversion of nuclear material is a sine qua non, technology extensively undergirds modern approaches to adequately monitor and safeguard both fissile inventories and nuclear facilities per se. Pertinent technology is also able to make fissile material innately more difficult to access and divert, and can greatly enable reduction in both the numbers and the scales of sites from which material could be diverted, thereby enabling more effective safeguarding efforts.

Although policy is a central — and complex - aspect of nuclear sustainability, it is not considered further in this paper, which is primarily focused on the purely technological aspects of nuclear sustainability. Instead, the reader is invited to read [13] for a recent overview of the issue-set.

\subsection{Range of Applicability}

While not directly bearing on an energy technology's sustainability, the range of applicability of the technology determines the degree to which it can be employed and therefore how much impact it can have on the sustainability of the global energy system as a whole. Range of applicability considerations include several components: over what geographic areas the technology can be implemented, which end-use applications can be served by the technology, and what are the abilities of the technology to service variations in demand for energy services, on time-scales ranging over minutes to months. It also implicitly includes economic factors as well: a technology may be applicable in principle in given circumstances, but unless it is able to do so in an overall cost-competitive fashion, it is unlikely to be exercised significantly. While resource availability gives the total amount of energy that can be supplied by a technology, range of applicability determines a complimentary attribute: the maximum amount of power that can be supplied.

For nuclear fission-derived energy to enable a sustainable global energy system, it should be applicable to a majority of significant energy uses, which include electricity production, transportation, most-if-not-all of the spectrum of industrial uses, water services, and commercial and residential heating and air conditioning, moreover in a large majority of global locales.

\section{Technologies Enabling Sustainable Nuclear Energy}

We now describe three technology-sets that, when concatenated, can realize a nuclear energy system that satisfies arguably all of the sustainability criteria outlined above. The first, uranium harvesting from seawater, has the potential to greatly extend mankind's readily-accessible supply of uranium. The second, manifestly safe breeder reactors, is a category of nuclear power reactors that have two important qualities: manifest safety, which is required for widespread and long-term operation with exceptionally low likelihood of accidents, and breeding of fissile fuel, which greatly increases the utilization of uranium and thorium fuel resources. One type of reactor in this category that is significant from a sustainability perspective is described for purposes of specificity: the traveling wave reactor (TWR), which is able to minimize - potentially to eliminate entirely - the amounts of fuel reprocessing and isotopic enrichment required and therefore qualitatively enhance the sustainability of the global nuclear fuel cycle. The third enabling technology is deep borehole disposal of nuclear waste, which currently appears to be exemplary of cost-effective, reliable, and scalable methodology for permanently disposing of all types of waste from nuclear energy operations. 


\subsection{Uranium Extraction from Seawater}

Uranium ions (predominately as uranium carbonate) exist in all seawater at a fairly uniform concentration of roughly 3.3 parts per billion, or 3.3 micrograms per liter [14]. This concentration is very low compared to the concentrations of hundreds of parts per million available in commercial uranium ores, but the vast volume of seawater on Earth means that the oceans contain on the order of one thousand times more uranium than can be obtained from known terrestrial ores of the quality-level presently deemed to be suitable for commercial processing. Moreover, seawater is vastly more 'accessible' and 'processable' than are typical uranium ores.

Extracting uranium from seawater has been demonstrated using fabrics and fine yarns comprised of 'designer materials' that selectively adsorb-and-retain — sequester-uranium ions, even in the presence of other dissolved ions present in far higher concentrations in seawater; from a functional perspective, these are sheets/blankets of ion-exchange materials with high specificity for uranyl ions. Thereby-sequestered uranium may be removed from such adsorbent materials by elution with dilute hydrochloric acid, a cheap-and-plentifully-available industrial chemical - and potentially by other means as well, including electrolytic ones - after which the adsorbing material can be recycled to harvest another batch of dissolved uranium from another mass of seawater. Materials have been developed and performance-demonstrated that adsorb up to 2 grams of uranium from seawater per kilogram of adsorbent after marine exposure-intervals of a few weeks each, with the adsorbent capable of being recycled at least a half-dozen times in experimental results reported to present. To be sure, commercial-scale extraction of uranium from seawater has not been demonstrated - by these or any other means-because doing so isn't currently cost-competitive with mining-and-processing of uranium ores. Costs of such seawater extraction have been estimated at roughly $\$ 1000 / \mathrm{kg}$ of uranium-produced when employing current technology, and $\$ 300 / \mathrm{kg}$ is deemed foreseeable with improvements in adsorbent technology [15]. (A half-decade ago, the 'spot' price of uranium in global commerce surged to $\sim \$ 300 / \mathrm{kg}$, though it is a few-fold less than this at present.)

Because of the low concentration of uranium in seawater, full commercial-scale extraction would require processing large volumes of seawater. Such large-scale systems would most likely rely on natural oceanic and riverine currents to move water through large arrays of deployed adsorber materials. These adsorber arrays could be moored in place and retrieved (periodically or continuously) for uranium-extraction - the approach employed in the concept-demonstration work performed through the present time - or they could be trailed-behind ships, either ad hoc ones which might sail slowly along circuits conveniently including processing-points, returning periodically to these points with their "catch" of uranium, or behind commercial oceanic freighters deploying them as "collateral payloads' during their ordinary oceanic transits. 


\subsection{Manifestly Safe Breeder Reactors}

A set of power stations containing various instantiations of the manifestly safe breeder reactor is the central component of the sustainable nuclear energy system described here. First, such reactors are sustainable from an environmental and social perspective because they operate with publically understood and accepted levels of risk of accidents involving significant releases of radioactive material to the biosphere. Second, they are sustainable from a resource perspective because of their ability to completely utilize the isotope uranium-238, which makes up $99.3 \%$ of natural uranium, rather than only a fraction of the $0.7 \%$ abundance uranium-235 isotope - a potential gain of $\sim 200$-fold; this far-greater use-efficiency enables all-ways-practical recovery of uranium from seawater, thereby providing a known-and-effectively inexhaustible supply of reactor fuel. From a sustainability perspective, the ideal breeder reactor is represented by the traveling wave reactor, which is able to minimize - asymptotically, to zero levels - the amounts of isotopic fuel enrichment and fuel reprocessing needed throughout its fuel cycle.

\subsubsection{Manifestly Safe Reactors}

The idea of "manifest safety" is the combination of two simple concepts: engineering to a very high degree of safety, and making the safety characteristics of a system transparent and fully known to everyone. Achieving manifest safety is crucially important to any nuclear energy infrastructure, not just one aimed at providing long term sustainability. The necessity of a high degree of safety is readily apparent, since accidents need to be avoided wherever possible, most especially so when significant releases of radioactivity to the biosphere may be involved. (Plant damage of other natures involves capital-at-risk in more ordinary industrial contexts, and can be aptly managed with commercial insurance - with its likelihood readily assessed via the magnitude of the insurance premiums charged by insurance underwriters.) Making this safety manifest is also necessary because the public can be directly impacted by accidents involving releases of radioactivity, and are therefore active stakeholders in the radiological safety of nuclear power plants: they continually benefit from cheap-and-abundant power sourced with exceptionally low environmental impacts while bearing the externalities costs associated with possible major releases of radioactive material.

Improving nuclear safety is a topic as old as nuclear energy itself, so only the topic's most salient points will be very briefly summarized here. The key to achieving a high level of safety is to have defensive measures at each stage in any possible accident sequence, and furthermore to layer such defenses at each stage so that it takes a combination of many simultaneous, independent failures to defeat a given stage - an approach referred to as "defense in depth." To the greatest extents possible, such defenses should operate entirely independently of operator inputs and instead should appeal entirely to physical mechanisms and natural phenomena (e.g., motions of masses under gravity, passive thermal conduction, circulation of differentially-buoyant fluids, etc.) for the totality of their essential functions.

The key stages of accident interdiction are guarding against accident initiators, ensuring reactor core shutdown and afterheat removal, and preventing significant radiological releases to the biosphere. The first stage prevents accidents from occurring in the first place, and includes stringent construction, 
operation, and maintenance practices supported by a pervasive safety culture, as well as sensors and inspections that fully indicate the state of the plant at any moment. Accidents occurring due to external initiators (most notably earthquakes, but including extreme meteorological conditions and inundation) can be effectively precluded by apt use of remote seismic and weather monitoring, appropriate structural engineering for the site of interest, and seismic isolation/dampening for critical components and systems.

The second stage, ensuring core shutdown and afterheat removal, prevents an accident sequence from progressing to the point of core damage. The major technological advancement in improving defenses at this stage is the development of passively safe reactors, i.e., reactors that are able to automatically shut down and remove afterheat with no operator inputs and no electrical power. This is accomplished by providing redundant, automatic shutdown systems, as well as adequately large thermal masses (e.g., graphite in the core, large tanks of water, or the atmosphere itself) to serve as heat sinks, and means to flow afterheat to the heat sinks based on conduction and natural convection. Passive safety is quickly becoming a standard feature in new nuclear power plants, such as those centered on the Westinghouse AP-1000 reactor and is a defining characteristic in most other advanced reactor designs. Its benefits are borne out by probability risk analyses, which show that reactors with passive safety systems have core damage probabilities that are two orders of magnitude lower-i.e., $100 \mathrm{X}$ smaller - than those without [16]. In addition to passive safety, some types of reactor (e.g., molten salt reactors and some sodium-cooled fast reactors) are able to achieve inherent shutdown, meaning that even if all shutdown systems fail, naturally occurring reactivity feedbacks cause the reactor to shut itself down when internal temperatures increase beyond normal operating levels [17] while remaining adequately below levels at which structural damage might ensue.

The third stage is aimed at preventing radiological releases to the biosphere in the event that the core is damaged. This can be achieved in a definitive manner by underground siting of the reactor core, allowing the core to be totally isolated from the biosphere at a moment's notice. It is also possible to design reactor containments with predefined "escape routes" for e.g., volatile material that would tend to escape during a severe accident involving breach-of-containment, and to employ filters and cold traps along these routes to retain and thereafter sequester radioactive materials. Escape of solid or molten fission products can be prevented by employing one or more "core catchers"- featured in some modern Russian reactor designs and the European Pressurized Reactor-beneath the core that are able to trap and immobilize any downfalling molten core material.

Individually, many of these safety measures could have prevented entirely or at least mitigated substantially the three major accidents in the history of civilian nuclear power: the severe incident at Three Mile Island (which injured no one and released no radiation above normal limits at the plant's site-boundary, although the reactor's core was seriously damaged), the Chernobyl catastrophe (which killed five dozen people and induced roughly 100 non-fatal cancers in juveniles) and the Fukushima Daiichi disaster (which while killing no one, effectively destroyed one of the world's largest electric utilities and induced major dislocations in a great nation's basic energy posture). Implemented together, they have the potential to ward off nuclear power plant accidents in all but the most devastating natural or military circumstances, and to successfully mitigate severe consequences of most if not all of them which nonetheless might occur. 
The second key aspect of manifest safety is fully communicating the safety characteristics of any and all nuclear power reactors to the global nuclear power community - which must jointly defray the externality costs of nuclear power - and to the general public, which will rationally insist on proper accounting for these costs. Making safety manifest is enabled to a degree never before possible by modern data recording, storage, processing and transmission capabilities - the costs of all of which continue to decrease exponentially with time at Moore's Law rates - and by nearly ubiquitous and instantaneous public access to such data through the swiftly-advancing capabilities of the Internet.

As a basic aspect of communicating manifest safety, the measures just described must be implemented in a fully transparent manner, from design to construction and on through operation and eventual decommissioning, in order to support unceasing professional-peer and general-public reviewing of the safety postures of each-and-every nuclear power plant, around the world.

Secondly, integrated results from this ongoing safety reviewing by peer-professionals must be effectively conveyed to the public. One important element of such communication likely would be a universally accessible website - e.g., a nuclear power analog of an arXiv-Wikipedia hybrid—operated by professionals of unquestioned expertise and objectivity that provides up-to-date risk information and net assessments regarding each power reactor anywhere. This information would be based on probabilistic risk assessment analyses that provide order-of-magnitude forecasts of core damage and radioactive release probabilities, taking into account current conditions of each plant such as its design-and-construction, its operational history-and-status, equipment condition, and anticipated probability of major external events such as earthquakes, inundations, attacks, etc.

Information of such quality, timeliness and completeness would make it adequately clear to the public, as well as to regulators and political decision-makers which plants are most susceptible to which types and levels of risks and for what reasons. For example, such a service could have revealed the relatively severe susceptibility of the Fukushima Daiichi nuclear power station to tsunamis, which had been known prior to the 2011 Tohoku Earthquake [18,19] but which facts were not disseminated to degrees sufficient to politically compel corrective actions. Possible issues of intrusiveness into 'internal affairs' of utilities and owner-nations were settled rather definitively in the aftermath of the Chernobyl catastrophe, as nations sharing the Eurasian continent and its airspace demanded, oversaw and co-sponsored the safety upgradings or retirements of nuclear power reactors that shared the shortcomings of the Chernobyl design.

A third component of adequately communicating all possibly-pertinent safety information would be comprehensive, quantitative studies of total health impact of different energy sources, where such health consequences are measured in the widely-used unit of disability-adjusted life-years (DALYs). Such a component could provide objectively-defensible results - based on transparent choices-made regarding modeling parameters - with respect to both DALY gains (e.g., arising from improved levels of health and life-expectancy directly and indirectly resulting from greater levels of electrification and societal energy-intensity) and DALY losses (e.g., due to anticipated pollution/radiation releases during mining-and-deployments, reactor operation, and waste management) to both the energy-sourcing professional community and to the energy-consuming general public and its political leaderships.

These ongoing studies in turn would enable informed public debate regarding which energy technologies in which particular modalities are the most sustainable, economically preferable and 
overall desirable from health-and-welfare perspectives. The nuclear power component of such studies and debates likely would benefit greatly from ongoing research quantifying the fundamental health impacts associated with low total doses and dose-rates of ionizing radiation, such as [10]. These MIT studies reported that no genetic damage could be detected even after continuous irradiation at 400 times natural background dosing-rates, up to 0.1 Gy total-dose levels - which dosing-rates and total doses both were very greatly in excess of all exposures of the general population seen in the aftermath of the Fukushima Daiichi disaster.

\subsubsection{Breeder Reactors}

There are many reactor and fuel cycle options (including options that incorporate light water reactors) that are able to extend uranium (and thorium) resources for many decades or even centuries. In this paper, special attention is paid to breeder reactors operating in a uranium fuel cycle because of their unique ability to efficiently use the vast amounts of uranium present in the oceans, which enables a nuclear infrastructure that is able operate for many millennia.

Phrased most concisely, a breeder reactor is a nuclear reactor that creates more nuclear fuel than it consumes. This is possible because of the difference-in-kind between fissile and fertile nuclides. First, there are fissile nuclides, such as uranium-233, uranium-235 and plutonium-239, which are easily fissioned-i.e., by the relatively low energy neutrons of the types available in nuclear reactors - and can therefore sustain a fission chain reaction; these nuclides are properly thought of as the "fuel" of a nuclear reactor. Second, there are fertile nuclides, such as thorium-232 and uranium-238-whose natural abundances are far greater than those of the fissile nuclides-which are more difficult to fission-i.e., are not readily fissioned by neutrons available in nuclear reactors - and therefore unable to sustain a neutron-coupled chain reaction by themselves. However, these nuclides are "fertile" because they can be converted into fissile nuclides by absorbing one neutron per nucleus, thus becoming readily fissionable via successive absorption of two neutrons (in contrast to the single neutron absorption event which suffices to fission a fissile nuclide). A breeder reactor is a reactor-type that converts fertile nuclides into fissile ones at a greater rate than it consumes fissile nuclides - because it can produce-and-utilize more than two neutrons for each fission that occurs within it - so there is a net production of fissile nuclear fuel, even as fissile nuclides are being consumed by the energy-producing fission process.

The basal significance of breeder reactors for nuclear sustainability is evident from considering the natural abundances of fissile and fertile nuclides. Of the two naturally-occurring uranium isotopes (not counting trace quantities of uranium-234), only $0.7 \%$ is fissile uranium-235, while the remaining $99.3 \%$ is fertile uranium-238. The other naturally-occurring nuclear resource is thorium, which consists solely of fertile thorium-232. Non-breeder reactors (such as standard light water-cooled reactors, or LWRs) burn primarily uranium-235, while converting-and-fissioning only a fractional amount of uranium-238, and therefore liberate only about $0.6 \%$ of the total energy content of as-mined uranium (assuming $\sim 0.25 \%$ U-235 depleted uranium tails from the enrichment process). Breeder reactors are able to effectively burn up to $100 \%$ of uranium-238 or thorium-232 by first converting it into fissile fuel, and are therefore able to increase the energy effectively available from uranium resources by two orders of magnitude - as well as to enable utilization of thorium resources, 
which are several-fold more abundant than are uranium ones in mined ores. Net, breeder reactors offer roughly 500 times greater energy production from crustal resources of the two actinide elements than do LWRs - which reactor types, however, were arguably the easiest to realize when military power reactor developments commenced six decades ago and an abundance of enriched uranium from military production facilities made efficient fuel utilization seem to be of secondary significance within the perspective of those times.

Many different types of reactors can be made to operate as breeder reactors, including ones employing sodium, lead, and various gases as their coolants, molten salt-based reactors, and even thermal-spectrum light-or-heavy water-cooled reactors using thorium as fertile material. All of these reactor types can be engineered to be manifestly safe in all aspects of their operations.

Breeder reactor technology was extensively researched and performance-demonstrated in the $1950 \mathrm{~s}$ and $60 \mathrm{~s}$, but never reached full commercial implementation for several reasons. First, there are enough conventional uranium resources available to fuel non-breeding light water reactors for many decades at current usage rates, so the economic incentive for improving nuclear fuel utilization has not been sufficiently strong to by-itself drive adoption of breeder reactors. Second, breeder reactors to date have mainly been deployed as research systems rather than exemplary commercial systems, and therefore have not been able to demonstrate via full-scale deployments the economic advantages that could drive their widespread adoption. Finally, interest in breeder reactors waned, at least in the United States, with the political decision taken a third-century ago to move away from reprocessing of spent reactor fuel assemblies (a topic discussed below in subsection 3.2.3), since such fuel reprocessing was then perceived - incorrectly, as has been realized much more recently - to be a sine qua non for breeder reactor feasibility.

\subsubsection{Traveling Wave Reactors}

Traveling wave reactors (TWRs), also known as "breed-and-burn" reactors, are a distinct subset of breeder reactors currently under development that can be refueled indefinitely using fuel that is entirely fertile, with no fissile content whatsoever [20-22]. One example TWR design currently being pursued uses unpressurized sodium coolant, ferritic-martensitic steel core structural material, and metallic uranium fuel [23,24].

In non-TWR types of breeder reactors, new fissile fuel is bred in fuel assemblies containing fertile material. Often, breeding is enhanced by the use of "blanket" assemblies containing predominantly fertile material, which are distinct from the power-and-neutron producing "seed" assemblies, which contain a relatively high concentration of fissile material. In order to create new fuel assemblies, bred assemblies must undergo "reprocessing", i.e., a recycling process in which fissile material is separated from bred assemblies and incorporated into new fuel.

In basic contrast, in a TWR, bred fuel is directly used to produce power and excess neutrons in the same fuel assembly, without ever having to undergo reprocessing and fuel assembly fabrication steps. There is no distinction between power-producing "seed" assemblies and fertile fuel-bearing "blanket" assemblies: fuel starts off with a high fertile content like blanket fuel, but is also capable of producing power, similar to seed fuel. The primary technology challenge in developing a TWR centers on the fact 
that a relatively high level of neutron irradiation is required to both breed fertile input-material into fissile fuel and then burn it in order to keep the reactor running.

With fuel assemblies capable of withstanding sufficiently-high levels of neutron irradiation, it becomes feasible for a TWR to be reloaded indefinitely with only fertile fuel, such as natural uranium or depleted uranium, i.e., uranium that is $>99.3 \%$ uranium- 238 , due to having been previously depleted of its uranium-235 fraction in an isotopic enrichment plant, and thus being 'waste' from such a plant [22]. Such TWRs would require just a single initial loading of fissile material-enriched starter fuel from an isotopic enrichment or fuel assembly reprocessing plant, in profound contrast with the continual loadings of fissile material-enriched fuel required by nearly every other type of extant power reactor. (There are non-breeder reactors that can operate using unenriched natural uranium as fuel, most notably the heavy water-moderated CANDU type and the graphite-moderated Magnox type of reactors, but these reactors operate by fissioning the very small fraction of fissile uranium-235 present in natural uranium, rather than by converting fertile uranium-238.)

Depending on the level of technological maturity achieved, several variants of TWRs with distinct operational characteristics are possible. Possibly the most straightforward is one in which the "wave"-i.e., the power distribution in the core-is approximately stationary at the center of a core, and fuel is 'shuffled' (i.e., purposefully moved) periodically in order to keep the "standing wave" in place. This variant enables minimization of the level of neutron irradiation of any given fuel assembly in the reactor core, because any such fuel assembly may be removed from within the wave when its neutron irradiation level attains a predetermined value.

A second variant is one in which the fuel is stationary and the power-producing wave moves through it [20]. This variant is the origin of the name "traveling wave reactor", and is also referred to as a "CANDLE reactor" [25], because a cylinder of fertile nuclear fuel would be fission-burned axially in the same basic manner as a candle burns. This second variant has the operational advantage of not requiring fuel shuffling, which means the reactor can generate power for much longer intervals and with few-if-any major operator actions, but generally results in an increase in the peak level of the fuel's neutron irradiation.

A third TWR variant is one in which fuel discharged from the TWR core (which has already been exposed to a high level of irradiation) still has significant useful life left. Such fuel can therefore be directly used as starter fuel for a new generation of TWRs, thus enabling the population-and correspondingly the aggregate power production - of a TWR fleet to grow exponentially in time without ever requiring any additional fissile input from a fuel-reprocessing facility or isotopic enrichment plant [26]. An intriguing sub-variant is the idea of a "TWR-like" molten salt reactor, i.e., a molten salt reactor that directly accepts fertile material as fuel, and can operate with only limited incore or in-loop fuel processing - rather than requiring fresh fissile fuel from a separate processing facility — while outputting entirely-ready-to-use fissile-rich fuel for loading into daughter-generation reactors of the same type.

Since all of these TWR variants require just a single loading of fissile starter fuel — and potentially only in the first of arbitrarily-many generations of reactors, at that - they can be used to minimize to ever-lower levels the amounts of isotopic enrichment or spent-fuel reprocessing in a nuclear energy system, and asymptotically to obviate entirely the need for either of these. 


\subsection{Deep Borehole Disposal of Nuclear Waste}

Deep borehole disposal is just what its name suggests: it involves drilling a comparatively deep ( $\sim 5 \mathrm{~km}$ sub-surface) borehole into the Earth's crust via repurposing of already-highly-developed petroleum-extraction technologies, stacking canisters containing waste-streams from nuclear power reactor cores at the bottom of the borehole, then plugging - 'stemming', in the jargon of such arcane practices - the uppermost $\sim 3 \mathrm{~km}$ of the hole with rock and cement. Research is currently ongoing to assess the practicality of the deep borehole disposal concept as a practical alternative to mined geologic repositories, such as the one originally planned for the Yucca Mountain site [27]. The safety of deep borehole disposal is discussed in [28], and relevant policy considerations can be found in [29].

Deep borehole disposal has several distinguishing features. First, it sequesters material at a much greater depth than is available in mined repositories $(\sim 5 \mathrm{~km} v s . \sim 0.5 \mathrm{~km})$, so that thereby-disposed radionuclides are physically much further from the biosphere. It has much less reliance on engineered barriers; the position and natural environment of the borehole is deemed sufficient to indefinitely sequester essentially all material, based in part on the now-extensive experience of the deep-drilling community in the service of the hydrocarbon-fuels extraction business sector. The ideal type of rock for borehole disposal (geologically stable, crystalline, low-permeability 'basement rock' such as granite) is widespread globally. Borehole disposal is also scalable to smaller sizes than mined repositories, allowing practical use of a far greater number of disposal sites, likely located much closer to where waste-stream is being generated. Compared to mined repositories, retrieval of nuclear materials from deep boreholes would be very challenging under the best of circumstances, and thus clandestine retrieval would be effectively impossible.

The basic reason that deep borehole disposal is likely to be highly effective is that there is effectively no material transport between rock at $5 \mathrm{~km}$ depths and either the surface or underground aquifers. Any water at those depths is highly saline and effectively immobile, as well as chemically reducing, which means that most constituents of disposed fuel would not become dissolved in it. One notable exception is radioactive iodine-129, which could dissolve and slowly diffuse upward through the path of the borehole plug if a borehole were to become filled with groundwater. Calculations show that this diffusion occurs so slowly that even if the borehole were hydraulically connected to an aquifer, the maximum radiation dose to individuals in worst-case would be roughly ten orders of magnitude - a factor of 10 billion - below IAEA-recommended limits [27]. In any case, the borehole plug can be designed to seal against such releases, eliminating this last miniscule source of potential contamination from borehole-disposal.

Like the other technologies described, deep borehole waste-disposal technology has been studied extensively but not yet demonstrated at commercial scale. The major impediments to implementation are characterizing the cost and performance of borehole disposal, and the regulatory challenges involved in obtaining licensing of any disposal site or modality. From a technological standpoint, the first impediment is being overcome by improvements in drilling technology and rock characterization driven by the oil/gas and geothermal energy industries, as noted above. Estimates of borehole disposal costs currently compare favorably to both the nuclear waste fee of $1 \mathrm{mil} / \mathrm{kW}-\mathrm{h}$ long-since collected by the U.S. government from utilities, as well as the estimated costs of a mined geologic repository, even in the case of much higher volume LWR spent fuel [28]. Costs can be reduced further by use of 
directional drilling techniques to create (potentially, highly-) branched boreholes with (much) higher total disposal capacity per unit of hole-length drilled. The second impediment may be overcome by applying the principles of manifest safety: i.e., rigorously analyzing, objectively monitoring and continually communicating the risks and benefits associated with borehole disposal technology.

\section{Sustainable Nuclear Energy Systems}

Integration of the three nuclear technologies overviewed above potentially enables a long-term-sustainable nuclear energy infrastructure of full planetary scale. Uranium extraction from seawater bids to greatly increase the amount of uranium readily available for use, while breeder reactors greatly increase the energy extractable from uranium-and also from thorium, as well. Manifestly safe reactors will encounter accidents that lead to core damage only extremely rarely, while significant releases of radioactivity to the biosphere will be far rarer still. Deep borehole disposal is exemplary of several distinct technologies that can be used to safely and permanently dispose of nuclear waste.

We now describe and characterize two variants of a sustainable nuclear energy infrastructure relative to the sustainability criteria laid out earlier. The first instance is centered on standard breeder reactors in conjunction with chemical reprocessing of spent fuel. The second is based upon traveling wave reactors and foregoes reprocessing entirely. Both hypothetical "global scale" nuclear infrastructures are assumed to generate $3.3 \times 10^{21} \mathrm{~J}$ of thermal energy per year (convertible to $\sim 1.3 \times 10^{21} \mathrm{~J}$ of electricity, i.e., a time-average power-level of $\sim 40 \mathrm{TWe}$ ), which corresponds to roughly 30,000 power reactors each of $\sim 1.3$ GWe capacity-rating. This amount of power is sufficient to supply all of the energy needs of 10 billion humans, each with per capita energy usage equivalent to that of present-day Americans. This is necessarily an idealization: total energy demand in the future may be substantially higher or lower than this reference level, and it's virtually certain that other energy sources will be used in addition to nuclear ones.

\subsection{System Using Standard Breeder Reactors}

Employing standard breeder reactors and reprocessing plants, it is possible to fission nearly $100 \%$ of all uranium (i.e., with some small fraction being not recovered during fuel-reprocessing). Complete fissioning of one kilogram of uranium is sufficient to provide $8.1 \times 10^{13} \mathrm{~J}$ of thermal energy, so annual production of $3.3 \times 10^{21} \mathrm{~J}$ corresponds to fissioning of $\mathbf{4 1 , 0 0 0}$ metric tonnes of uranium per year. This uranium use-rate is actually smaller than the current global uranium demand of $\sim 70,000$ MT per year [30] which however provides a far-smaller amount of energy-eloquent testimony to the vastly improved uranium utilization achievable with breeder reactors.

Harvesting this amount of uranium from seawater would involve efficiently extracting the uranyl ions from approximately $1.4 \times 10^{13} \mathrm{~m}^{3}$ of seawater a year, corresponding to an average flow rate of 0.43 Sverdrups (i.e., 430,000 $\mathrm{m}^{3}$ per second) through the extraction system. Such flow rates of seawater are readily available from natural currents; for example, the Florida Current carries about 30 Sv through the Straits of Florida, so only a small fraction $-1 \%$ - of even this modest current would need to have its dissolved uranium harvested to satisfy all of the energy needs of an energy-replete, fully-populated human civilization. Using the early adsorbent technology that's already demonstrated 
to be able to harvest $2 \mathrm{~g}$ of uranium per $\mathrm{kg}$ of adsorbent [15], and assuming a total collection cycle-time of two months, the amount of adsorbent material needed to be deployed at any given time would be roughly $\mathbf{3 , 4 0 0 , 0 0 0} \mathrm{MT}$.

With already-demonstrated technology, adsorbent materials can be reused six times, so the average adsorbent production rate would need to be at most 3,400,000 MT/y. (By way of comparison, current global production of oil is approximately 4,000,000,000 MT/y, over 1000 times larger.)

The minimum of $12 \mathrm{~g}$ of uranium produced from each $\mathrm{kg}$ of adsorbent (at least 6 use-cycles $\times 2$ gm-U extracted/cycle) can produce $1 \times 10^{12} \mathrm{~J}$ of thermal energy, equivalent to approximately 40 tons of coal. Improved adsorbent technology capable of adsorbing $4 \mathrm{~g}$ of uranium per $\mathrm{kg}$ of adsorbent and being used 18 times would reduce the required adsorbent production rate to $600,000 \mathrm{MT} / \mathbf{y}$ while increasing the energy yield per $\mathrm{kg}$ of adsorbent to $6 \times 10^{12} \mathrm{~J}$, equivalent to 240 tons of coal. Masses of this magnitude are not at all unprecedented for deployment at sea; for example, oil supertankers capable of carrying over 500,000 MT have been built and operated.

Producing new fuel for the reprocessing variant of this nuclear energy system would require quite substantial reprocessing facilities, which would recycle used seed and blanket fuel into fresh seed fuel. The total reprocessing capacity needed would be larger than the amount of uranium needed, because fuel exiting the breeder reactors would only be incompletely burned. If the average discharge burnup level (taking into account both seed and blanket fuel) is taken to be $9 \%$, then the total reprocessing capacity would be $(41,000 \mathrm{MT} / \mathrm{y}) / 9 \%=460,000 \mathrm{MT} / \mathrm{y}$. This corresponds to roughly $\mathbf{6 0 0}$ commercial-size reprocessing plants with capacities of $800 \mathrm{MT} / \mathrm{y}$, each servicing about 50 reactors. This number is inversely proportional to average burnup, so breeder reactors that achieve higher burnups would require less reprocessing capacity.

On the back end of the nuclear fuel cycle, waste will be produced mostly in the form of fission products and used cladding hulls from the reprocessing facilities. Some small amount of actinides will be lost during reprocessing as well and would be disposed of as waste. Finally, radioactive facility wastes created during reprocessing operations may also need disposal. Estimates for waste volumes from a pyrometallurgical reprocessing facility are $0.3 \mathrm{~m}^{3}$ of ceramic waste (containing most of the fission products) and $0.05 \mathrm{~m}^{3}$ of metal waste (containing some fission products, zirconium from the fuel-alloy, and stainless steel cladding hulls) per MT of fuel processed [31]. The volume of low level wastes generated is expected to be small compared to these high level wastes, because pyrometallurgical processes are able to reuse all their process fluids. One advantage of employing reprocessing is that nearly all of the long-half-life actinides are recycled, so the high level waste that is produced decays relatively quickly. Such waste would become less radiotoxic than natural uranium ore within a timescale of centuries to millennia, potentially easing disposal requirements.

Given these waste volumes, the total volume of waste generated each year would be roughly

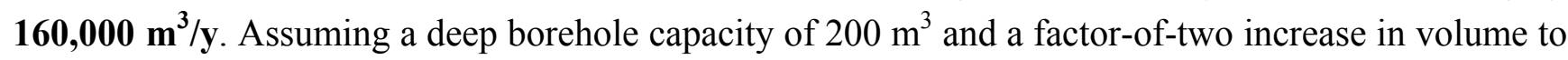
account for packaging, this corresponds to roughly 1600 new boreholes - or borehole branches, if directional drilling is used for trunk-and-branch generation of disposal sites - per year to accommodate the wastes generated by a 30,000-reactor global nuclear energy system. Assuming a borehole-toborehole spacing of $100 \mathrm{~m}$ and no usage of the trunk-and-branch option, these 1600 boreholes required for annual global disposal would occupy an area of about $\mathbf{1 6} \mathbf{~ k m}^{2}$, which is about $0.5 \%$ of the total area of the Nevada Test Site — so that an NTS-sized area would suffice for two centuries of deep borehole 
disposal of all nuclear energy system wastes from energizing the entire planet. As another way to think of it, each borehole would be capable of storing roughly 20 years' worth of waste from each reactor, so only 2 or 3 unbranched boreholes would be needed over the operational lifetime of a reactor to dispose of its wastes, adding a small additional area to the 'footprint' of a plant.

This energy system exhibits several synergies between its various technologies. First, the small amount of uranium required by breeder reactors means that the procurement of uranium would involve only a very small fraction (less than $1 \%$ ) of the present-day cost of electricity. This means that more expensive sources of uranium, such as that adsorptively extracted from seawater, can be used in an eminently economical fashion. Second, waste volumes are minimized because of the high fuel burnups achieved in breeder reactors, and because most of the fuel constituents are recycled to form new fuel. This synergizes well with borehole disposal, since the amount of waste that can be disposed of in a borehole is primarily limited by borehole volume, unlike in mined repositories which are limited by heat load from radioactive decay processes. Therefore boreholes are a natural choice for low volume, high specific heat-rate breeder reactor waste, in contrast with comparatively high volume, low specific heat-rate LWR waste. Third, the relative permanence of borehole disposal is more applicable to a breeder reactor system than to an LWR one. This is because the disposal of potentially useful plutonium fuel is no longer a concern when using breeder reactors, due to the facts that they are capable of producing additional fissile fuels (i.e., uranium-233 and plutonium-239) as needed and that they employ inputted uranium-and-thorium with such exceptionally-high mass efficiency.

\subsection{Systems Using Traveling Wave Reactors}

The most fundamental distinction between a nuclear energy system based on TWRs and one using conventional breeder reactors is that the TWR system does not require reprocessing in its fuel cycle.

Two variants of the TWR system are considered here. The first variant uses "once-through" TWRs that are started using a single-time fuel load of enriched uranium-although "war surplus" plutonium-239 would be a fine substitute for the uranium-235. Using likely near-future technology, it is estimated that roughly $8 \mathrm{MT}$ of fissile uranium-235 is required to start up a single commercial-size ( $\sim 3$ GWt) TWR. Once started, the TWR only consumes fertile fuel, which can include natural uranium as well as the depleted uranium created during the enrichment process for the initial fuel-load —or even spent fuel from LWRs. This TWR variant operates on a once-through fuel cycle: all of the fuel exiting from the TWR (e.g., at 20\% average burnup, employing contemporary fuel-cladding materials below their postulated neutron-irradiation limits) is dispatched to a disposal facility.

The second TWR variant uses a "spawning" mode-of-operation, in which used TWR fuel can be directly used a second time - without undergoing reprocessing - to serve as the starter fuel for a "daughter" TWR. This option uses a "twice-through" fuel cycle, in which natural or depleted uranium fuel is first used as fuel in a first TWR, then the now-bred fuel is burned up further to start up the core of a "daughter" TWR, and finally this twice-burned fuel is disposed of in a deep borehole. This second, more technologically advanced sub-variant has the advantage that new TWRs do not require additional input of fissile fuel from either an isotopic enrichment facility or a reprocessing plant: the life-trajectory of all actinide fuel goes directly from mine or seawater-sourcing through one-or-at-most-two TWR cores for energy production and from there to permanent disposal. 
In both of these variants, each TWR core is potentially capable of propagating a fuel-burning wave indefinitely. In other words, even when a given TWR plant may reach the end of its declaratory service life (e.g., 60 years), the core of that TWR can be directly transferred to a new plant to continue operation. This drastically reduces the amount of enriched uranium needed to start up new TWRs in a TWR nuclear energy system, asymptotically to zero.

A TWR energy system would require uranium for two purposes: to serve as feed fuel for operating TWRs, and in the first variant, to create enriched fuel to start up new TWRs. For the first purpose, the amount of feed uranium needed for a $100 \mathrm{TW}$ fleet capable of energizing all of human civilization later in this century is equal to $(41,000 \mathrm{MT} / \mathrm{y}) / 20 \%=\mathbf{2 0 0 , 0 0 0} \mathbf{M T} / \mathbf{y}$, where $20 \%$ taken to be the average uranium burnup feasible with extant fuel-cladding materials.

For the second purpose, the amount of uranium required would depend on the rate at which new capacity is added to the TWR fleet. In the "stabilization scenario" in which global energy supply has leveled off, no additional uranium is needed because no new TWR capacity is being added, and no enrichment capacity would be needed either. Meanwhile, in the "growth scenario", a reactor fleet with an initial 30,000 GWe-class reactors and population-expanding at a 3\% annual rate would initially require 900 new reactors per year, which for the first variant (using "non-spawning" TWRs) would require $7200 \mathrm{MT}$ of fissile uranium, or about $\mathbf{1 , 4 0 0 , 0 0 0} \mathrm{MT} / \mathbf{y}$ of natural uranium, which is about 7 times greater than the amount needed for feed uranium. The reactor fleet growth rate at which these numbers are equal to each other is 7 times lower, or roughly $0.43 \%$ per year. (Put another way, each TWR requires $1 / 0.0043=230$ full-power years to burn through the depleted uranium 'tails' produced during its startup, given present-time baseline-design values for core power densities and fuel-burnup levels. Again, this is eloquent testimony to the exceptionally high uranium utilization achievable using breeder reactors.)

This means that for fleet growth rates higher than $0.43 \% / y$, the amount of uranium and enrichment needed in a once-through TWR energy economy is determined by its growth rate rather than what's needed to feed existing reactors. (Anticipated improved designs with higher power densities will require less than $8 \mathrm{MT}$ of fissile uranium fuel to start up, and therefore be able to sustain higher growth rates without increasing the uranium requirement.) With a 3\% growth rate, the TWR infrastructure requires $\sim 34$ times more uranium supply than the conventional breeder reactor infrastructure to start up new TWRs (versus just $\sim 5$ times more to keep the TWR fleet running). The required amount of seawater processing and adsorbent mass would scale up proportionally.

The amount of enrichment needed to produce new TWR starter fuel for a $3 \%$ growth rate is equivalent to $\mathbf{2 0 0}$ large enrichment plants, each with a capacity of 7,500 MT of separative work units (SWU) per year. This number is proportional to the TWR fleet growth rate, so for a global nuclear energy system with a stabilized energy supply, the amount of enrichment and reprocessing needed are each exactly zero. (As another sub-variant, one can also envision a system using "mostly once-through" TWRs fueled with reprocessed fuel rather than enriched uranium. In such a case, one would need to reprocess $\sim 80 \mathrm{MT}$ of used fuel to produce a starter for a new TWR, or 72,000 MT/y to start 900 reactors for a 3\% growth rate. This is about a third of the 200,000 MT of used fuel discharged from TWRs, and the remaining two-thirds would be sent to a disposal facility. The amount of reprocessing capacity needed in this sub-variant is a factor of 6 less than required by the standard breeder reactor system. Therefore, a non-spawning TWR system can be used either to eliminate 
reprocessing entirely and substitute it with enrichment or to greatly reduce the amount of reprocessing required (in "growth" scenarios), or to eliminate both reprocessing and enrichment entirely (in a "stabilization" scenario).)

These extra amounts of uranium and isotopic enrichment needed to start up additional TWRs for rapid fleet expansion can be avoided in several ways. First, technological advances in TWR burnup capability and power density are expected to significantly reduce the amount of fissile starter fuel required for each reactor, relative to current baseline designs. Second, the second TWR system variant using "spawning" TWRs would allow additional TWRs to be started up with used TWR fuel [25]; accomplishing this would require either advanced TWR fuels that are highly resistant to irradiation, or use of methods of reconditioning TWR fuel for reuse. In such a scenario, used TWR fuel would be burned in a second TWR from an average burnup of $20 \%$ to around $35 \%$, and in doing so supply additional neutrons that establish a self-propagating depleted-uranium-burning "wave" in the second TWR. Finally, it would be exceptionally straightforward to implement such a "spawning" fuel cycle by using "TWR-like" molten salt reactors that can efficiently consume fertile fuel without a separate processing plant; spawning in such a case would simply involve taking used fuel from one reactor and using it to start up an identical new core in a 'daughter' reactor.

In these TWR energy systems, there is no reprocessing of spent fuel (except for limited amounts in the sub-variant discussed two paragraphs above), so the "back end" of the fuel cycle consists solely of disposal (or a single instance of fuel reuse, in a twice-through "spawning" fuel cycle). A representative core-averaged uranium density in a TWR core is $\sim 2.5 \mathrm{~g} / \mathrm{cc}$ - this mass-fraction is coincidentally similar to the volume of waste produced from a reprocessing plant per unit mass of heavy metal

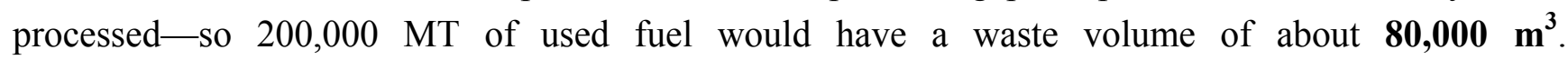
Again assuming a deep borehole capacity of $200 \mathrm{~m}^{3}$ and a factor-of-two increase in waste volume to allow for packaging, this corresponds to roughly $\mathbf{8 0 0}$ new boreholes (or borehole-branches) per year. This amount is about half that of the conventional fast reactor infrastructure, largely because TWR fuel assemblies achieve higher average burnups. Increasing the burnup of TWR fuel (for example if using a twice-through spawning fuel cycle) would proportionally further reduce disposal volumes and borehole populations.

The same synergies between seawater extraction of uranium, breeder reactors, and borehole disposal are present in the TWR system. The increased burnup of TWRs ( $20-35 \%$ of fuel-loaded $)$ relative to LWRs (4-6\% of fuel-loaded, or $\sim 0.6 \%$ of mined uranium, when isotopic enrichment wastage is considered) makes a TWR energy system far less sensitive to the price of uranium, and therefore able to utilize uranium extracted from seawater in an economically-practical manner. Meanwhile, the TWR energy system benefits fully from borehole disposal, because of its greatly-reduced waste volumes and its indifference with respect to irretrievable disposal of bred plutonium in the fuel-waste stream.

Figures 2 and 3 give the fuel cycle requirements for each type of nuclear system considered here, as well for a conventional once-through LWR scenario. Figure 2 assumes a stabilization scenario with 30,000 GWe-class reactors and no new capacity being added, while Figure 3 assumes a growth scenario with the same 30,000 reactors, but in which new reactor capacity is being brought online at a $3 \%$ annual growth rate, or 900 new reactors per year initially. 
Figure 2. Fuel cycle requirements in stabilization scenario.

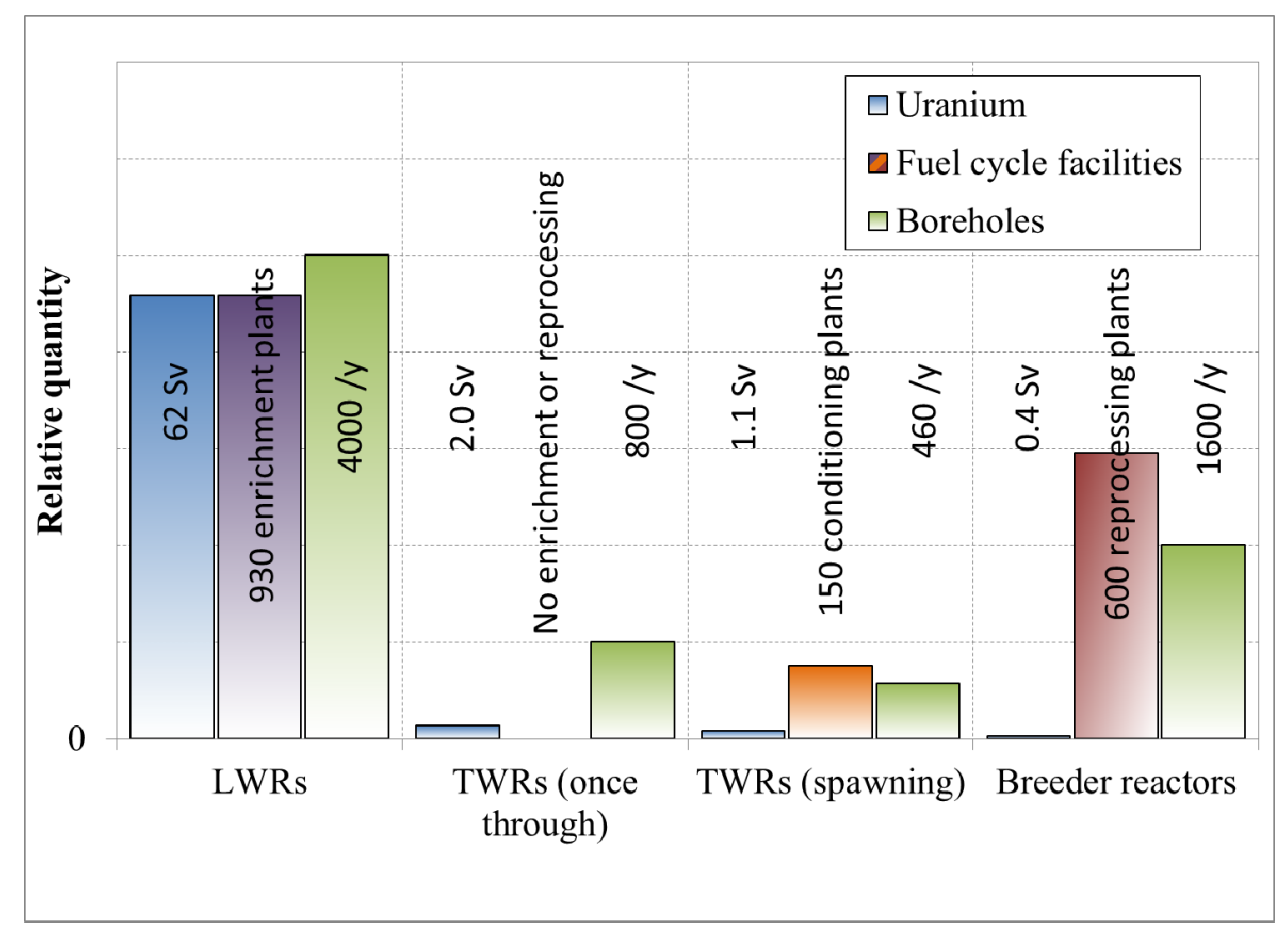

In Figures 2 and 3, the leftmost set of columns gives the uranium requirements for all four systems, in units of Sverdrups of seawater from which the uranium content would need to be harvested. The middle columns give the number of enrichment, reconditioning, or reprocessing facilities needed, assuming an enrichment plant capacity of 7,500,000 kg SWU/y, and reconditioning and reprocessing facilities with capacities of $800 \mathrm{MT} / \mathrm{y}$ of initial heavy metal, corresponding to large present-day enrichment and reprocessing facilities. The rightmost columns give the number of (unbranched) boreholes required to dispose of the high-level wastes generated.

For the stabilization scenario, Figure 2 shows that the conventional breeder reactor and TWR systems require far more modest uranium-flows than does the power-equivalent LWR system. The once-through TWR system has the unique advantage of not requiring any enrichment or reprocessing facilities to sustain continued operation of its reactor fleet. The spawning TWR system requires less uranium and creates less high-level waste because it is able to recondition its fuel to be burned more completely, but doing so would require a number of fuel-reconditioning facilities.

In the growth scenario, the standard breeder reactor and spawning TWR systems do not require additional uranium enrichment or fuel cycle facilities, because they already generate enough fuel for starting up additional reactors. They do require a somewhat larger amount of uranium to serve as feed material in newly started reactor cores. Meanwhile, the LWR and once-through TWR systems do require additional enriched fuel to be supplied in order to start up new reactors. Because the once-through TWR fleet does not require uranium isotopic enrichment or spent-fuel reprocessing facilities to keep existing reactors running, even in the growth scenario its uranium feedstream and isotopic enrichment requirements are one-fifth of that of an equivalent LWR fleet. 
Figure 3. Fuel cycle requirements in growth scenario (3\% annual growth rate).

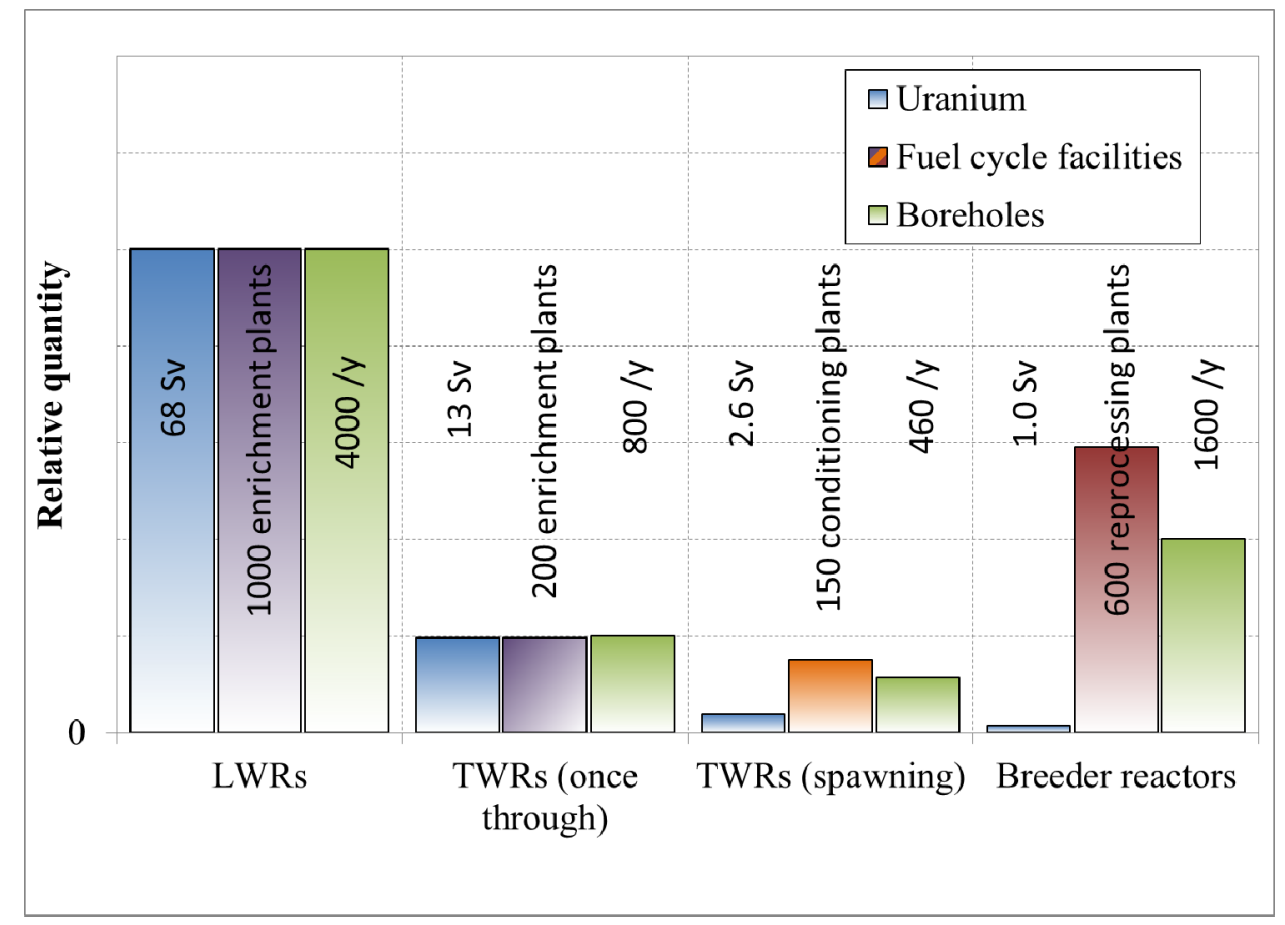

\subsection{Resource Availability}

Because the energy systems described source uranium from seawater, the amount of energy available to both is enormous by any standard. The amount of uranium presently contained in the oceans is 4.6 billion tons, a factor of 1000 greater than that contained in crustal ore sources which can be practically worked with extant mining-and-extraction technology. Used in a conventional breeder reactor energy system, this amount of uranium is capable of supplying an immense $\mathbf{3 . 7} \times \mathbf{1 0}^{\mathbf{2 6}} \mathbf{J}$ of useful energy, a factor of 37 larger than the value proposed as adequate for planetary-scale sustainability. This means that a small fraction of the uranium already present in seawater-and immediately available for adsorptive extraction-would suffice to supply all of mankind's terrestrial energy needs for many millennia at the $100 \mathrm{TW}$ global supply levels contemplated for the late 21 st century.

In a once-through TWR energy system with an average uranium utilization of $20 \%$ - versus $\sim 100 \%$ in the conventional breeder fuel cycle, or $\sim 35 \%$ in a 'spawning' type TWR system - the energy available from uranium is $3.7 \times 10^{26} \mathrm{~J} \times 20 \%=7 \times \mathbf{1 0}^{\mathbf{2 5}} \mathbf{J}$, a factor of 7 greater than the standard outlined for planetary-scale sustainability. Meanwhile, conservatively assuming that $8 \mathrm{MT}$ of fissile uranium is required to start up each TWR, the reference 4.6 billion tons of natural uranium-in-seawater would be sufficient for starting approximately 3 million TWRs with a total power level of 10 petawatts, $\sim 600$ times greater than presently used by human civilization-which as discussed in Section 2.1 is a terrestrial energy use level approaching the physical limits of what can be supported on Earth without a major increase in average planetary-surface temperature. Likewise, an infrastructure using "spawning" TWRs featuring higher uranium utilization— 35\% average fuel burnup — would be even more readily capable of supplying the full amount of energy and power to qualify as planetary-scale sustainable, according to the approximate criteria of present interest. 
Figure 4 shows the same "energy scenario" map as Figure 1, but with new contour lines corresponding to the breeder reactor and TWR scenarios, as well as contours corresponding to an LWR scenario and the approximate combined energy content of all recoverable fossil fuels (excluding methane clathrates).

Figure 4. Range of scenarios available with different energy sources.

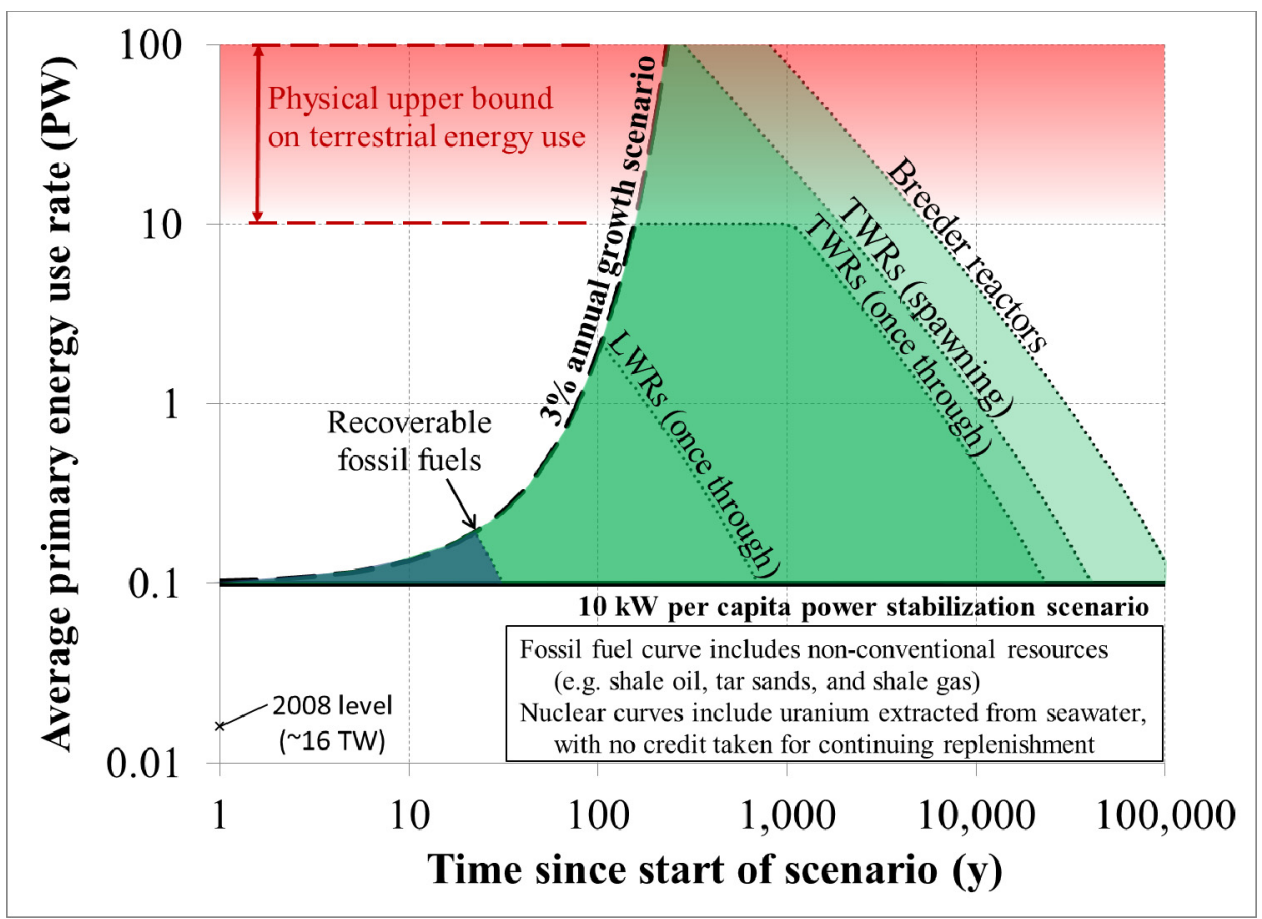

In Figure 4, the once-through TWR scenario contour line has a maximum at $1 \times 10^{16} \mathrm{~W}$, based on using 8 MT of fissile uranium to start up each new 3000 MW TWR; as discussed previously this "ceiling" can be raised with improved TWR designs requiring less starter fuel. The LWR curve assumes uranium utilization equal to $0.6 \%$ of the as-mined fuel, which can be improved to about $0.8 \%$ with reprocessing of LWR fuel or with re-enrichment of depleted uranium tails, albeit without discernible change to the Figure 4 plot.

Even without reprocessing or breeder reactors, use of uranium from seawater allows a LWR-based nuclear system to sustain itself for very long periods of time. However, fuel costs would be greater for LWRs than breeder reactors, because the factor of $\sim 160$ lower uranium utilization means that 160 times more natural uranium would be required to supply the same amount of energy, and therefore 160 times more infrastructure would be required to extract the requisite uranium-flow from seawater. Using only uranium from terrestrial ores would reduce the energy available for each nuclear scenario by a factor of between 100 and 1000, depending on what uranium concentrations in ore are deemed economical and/or environmentally-feasible to recover. Based on this consideration, large-scale breeder reactor systems can still be sustainable for multi-century timescales without requiring uranium from seawater, and the addition of seawater uranium resources enables them to become planetary-scale sustainable in the senses proposed in this paper.

One additional aspect of nuclear sustainability_noted long-since by Bernard Cohen - is that a significant fraction of the nuclear fission energy resource is in fact completely "renewable" in the same 
sense as wind and solar energy [32]. Wind and rain constantly erode the Earth's crust, which contains an average uranium concentration of 3 parts per million. Rivers then carry this dissolved uranium into the oceans, at a rate of approximately 10,000 MT per year [33]. In a breeder reactor energy system, this is a sufficient rate to supply the world's entire electricity demand at the present time more than five times over - or is roughly one quarter of what's needed to supply a continual 100 TW to a hypothetical global civilization of 10 billion persons which is energy supply-replete by any contemporary measure.

As the crust is being eroded by rivers, it is constantly replaced by new layers of rock being pushed upward by plate tectonic processes. The supply of uranium in the Earth's crust is effectively inexhaustible, on the order of 40 trillion metric tonnes, a factor of 10,000 more than is present in the oceans. At present erosion rates, this source of uranium would last on the order of 4 billion years, similar to the timespan over which the Sun will become a red giant.

Therefore, this assured source of "continually mined-by-Nature and oceanically presented" uranium will last as long as life on Earth does - even if burned at rates sufficient to supply a large fraction of a fully-developed human civilization - and represents an astronomical amount of nuclear energy, one that is in fact truly renewable and inexhaustible by any human measures.

\subsection{Environmental and Social Impacts}

For both types of nuclear energy systems described above, the high energy density and non-polluting nature of this type of energy mean that both perform exceptionally well along environmental impact metrics such as land use, habitat preservation, and greenhouse gas and pollutant (e.g., $\mathrm{SO}_{2}, \mathrm{NO}_{\mathbf{x}}$, fly-ash, carbonaceous and metallic particulates) emissions. On the front end, uranium mining or extraction from seawater can be made to have very little environmental impact, simply because of the relatively modest amounts of uranium required and the isotropically-negligible consequences of extracting it from seawater. The extremely high energy value of uranium fuel means the costs of habitat protection and restoration involved in its use have minimal impact on the economics of nuclear energy, and therefore even a conventional uranium mining operation is far more capable of paying for land remediation than other types of mining might be. As discussed previously, only a very small ( $\sim 1 \%$ of a single ocean current) fraction of oceanic currents would need to be processed to harvest sufficient uranium, so it will be possible to use spatially-diffuse collectors that do not disturb local habitats and can readily avoid protected areas. Uranium adsorbent materials and their mooring/ship attachments naturally would need to be appropriately engineered so as to not threaten ambient marine life to untoward extents. Meanwhile, the gradual rate of uranium accumulation means that uranium collection modules can move slowly — if indeed they need to be moved at all — and with correspondingly minimal fuel consumption.

As for the nuclear facilities themselves, 30,000 large nuclear power plants sourcing $30 \mathrm{TWe}$ would occupy an area on the order of $30,000-100,000 \mathrm{~km}^{2}$, a very modest aggregate area for providing the entire globe's energy needs of all types. Taking the continental United States as an example, its share of $\sim 1000$ reactors would occupy an area of 1,000 to $3,000 \mathrm{~km}^{2}$, equal to $\mathbf{0 . 0 1 3 - 0 . 0 4 \%}$ of its total land area. In comparison, the total area occupied by present day U.S. coal mining operations alone occupies approximately $8,000 \mathrm{~km}^{2}$ [34], not including areas disturbed by past mining. As another comparison, 
using the equivalent land area for solar collectors would produce about 20 times less peak power and 100 times less energy in the time-average than a nuclear system, due to the diffuse and intermittent nature of solar energy. Land area required for borehole disposal only increases the required area by a factor of $0.02-0.05 \%$ of the base plant area per year, implying the feasibility of colocation of plants and waste disposal boreholes — which may be a significant operational convenience.

As noted previously, the waste produced by nuclear reactors is small in volume due to the energy density of nuclear fuel, and can therefore be completely localized. Nuclear energy produces no dispersed atmospheric pollutants such as the sulfur and nitrogen oxides, particulate, soot, and heavy metal smokes that are released from burning coal or petroleum. Since pyrometallurgical reprocessing reuses its process fluids, it does not add significant volume to the nuclear waste stream, as noted previously. The absolutely-small volume of the resulting nuclear waste-streams means that it can all be disposed of geologically, e.g., via emplacement in deep boreholes.

Similarly, the lifecycle greenhouse gas emissions of nuclear energy are very small. A metastudy by Sovacool [35] of the contemporary nuclear energy system cites values of greenhouse gas emissions between 1.4 and $288 \mathrm{~g} \mathrm{CO}_{2}$ equivalent/kW-h of electricity produced; in comparison, fossil fuel combustion results in 500-1000 $\mathrm{g} \mathrm{CO}_{2}$ equivalent/kW-h. The huge range in LWR values is due to differences in both the study methodologies employed and the scenarios studied. The upper-end values are largely due to use of legacy gas diffusion enrichment plants powered by fossil-fuel generated electricity; in contrast, modern centrifuge enrichment plants are able to use 50 times less electricity per unit of enrichment, and $\mathrm{CO}_{2}$ emissions from enrichment plants can be eliminated entirely by utilizing nuclear- or renewable-sourced electricity. Both of the nuclear energy systems considered above greatly reduce mining and enrichment requirements below those of the current LWR-centered nuclear energy system, and therefore can achieve greenhouse gas emissions-levels several hundred-fold below those of fossil fuel power-equivalents.

In addition to these standard sustainability criteria, nuclear energy must also be judged according to the safety of its reactors and its fuel cycle, both in terms of accidents resulting in significant radioactivity release to the biosphere as well as the diversion of fissile materials to weaponry. Nuclear reactors are in principle capable of reaching the very low rate of $1 \times 10^{-6}$ major accidents per year of reactor operation, the rate required to make such accidents very rare in calendar-time even with a large nuclear fleet numbering in the many thousands. Using probabilistic risk assessment methods, such low accident rates have been credibly estimated for both light water reactors and breeder reactors employing passive safety systems $[16,36]$.

Achieving such a low rate in practice, as well as developing public acceptance of these remarkably low risk estimates, will not happen immediately. Even though modern computer simulations greatly improve the ability to predict and communicate accident risks, highly unlikely unforeseen situations may still arise, sometimes resulting in a major nuclear incident. Just as with the lessons-learned from earlier major nuclear accidents, such situations will need to be internalized by the global nuclear power community and incorporated into risk analysis models, in order to minimize the likelihood of their recurrence in future nuclear power operations and to continually advance the safety posture of nuclear reactors around the world. The engineering and operational diligence required to properly defend against potential risks is best ensured by a policy of manifest safety, in which there is unceasing global peer review and comprehensive and timely public knowledge of the state of safety at each-and-every 
plant site. While emphasis here is placed on nuclear reactor operations, this principle of manifest safety must also be applied to all phases of the nuclear fuel cycle, including nuclear fuel storage, processing, transportation, and disposal. Through implementation of technologies that make reactors safer and the continual multiaxial monitoring that's enabled by manifest safety principles, it will be possible to avoid nuclear accidents and significant radiological releases in all but the most severe and lowest frequency natural disasters.

The other key aspect of nuclear safety and sustainability is preventing diversion of fissile materials to the production of nuclear weapons. The key stages of the nuclear fuel cycle that especially need safeguarding are those involving plutonium-bearing fuel, because plutonium can be readily separated by chemical methods to produce weapons-usable material. These stages include when fuel is being burned in a reactor core, fuel reprocessing, storage and transportation, and disposition of spent fuel. It is challenging to divert fuel from a nuclear reactor because it is highly radioactive, is already within a guarded facility, and (in solid-fueled reactors) present in large assemblies that would be very difficult to divert surreptitiously - especially in facilities operated according to manifest safety principles (which necessarily involve extensive real-time video monitoring). It would also be challenging to divert used nuclear materials from a borehole disposal site, because the enormous depth of the borehole would make recovery expensive, time-consuming, and highly visible, e.g., by overhead means.

The areas that need the most robust safeguards against diversion therefore are the reprocessing facilities and storage and transportation of plutonium-bearing fuels - as indeed has been observed long-since. The approach taken currently, and the definitive approach for preventing diversion, is to make all fuel reprocessing a state-level activity, and to subject all reprocessing facilities to military-type levels of control, monitoring and physical-and-administrative security. Meanwhile, technological options are available that can reduce the amount of reprocessing required and therefore reduce the burden of safeguarding associated equipments. Improvements in fuel design can increase the burnup achieved in breeder reactors, meaning that less fuel needs reprocessing per unit of energy produced. Meanwhile, development of traveling wave reactors would enable a nuclear energy system that enjoys the benefits of a breeder-reactor infrastructure while foregoing reprocessing entirely.

Similarly, portions of the fuel cycle involving enriched uranium fuels need to be safeguarded. Even if the low-enriched uranium produced at an enrichment facility is not usable in a weapon, it is possible to divert it to a second enrichment facility that would further enrich it into weapons-usable highly-enriched uranium. Producing highly-enriched using low-enriched uranium as a feedstock requires much less enrichment work than starting "from scratch" with natural uranium, meaning that the second, proliferating enrichment facility can be made smaller and more clandestine.

Safeguarding enrichment facilities and enriched materials can be accomplished in the same manner as safeguarding reprocessing facilities and their products. First, a high level of physical and administrative security is needed to serve as a direct defense against potential diversion. Second, employing the principles of manifest safety would include continual peer and public monitoring that would be capable of detecting any irregularities or attempts at diversion. Finally, reactor technologies allowing increased uranium utilization are able to reduce the amount of enrichment needed and therefore the number of facilities needing safeguarding. For example, a TWR 
would be capable of running indefinitely using no enriched fuel beyond its initial starter fuel, while a TWR operating in a "spawning" fuel cycle would not require enrichment even for its initial fuel load.

\subsection{Range of Applicability}

Currently, nuclear energy is used almost entirely for production of electricity, accounting for $20 \%$ of U.S. electricity production and about $13 \%$ of worldwide electricity-sourcing [37]. Because nuclear fuel is so energy-dense, fuel transport costs are minimal, so a nuclear reactor can be sited independently of the location of uranium resources. While many reactors are sited near large sources of water (rivers, lakes, and oceans) for use as a heat sink, water requirements can be vastly reduced by using evaporative cooling towers, allowing reactors to be sited inland; for example, 44 of France's 58 reactors are sited inland, with 32 of these using cooling towers instead of direct cooling from a river or lake. It is also in principle possible to use air-cooling via dry cooling towers (at a modest cost in thermal efficiency), allowing nuclear power stations to be sited nearly everywhere, in the total absence of a supply of water for heat-rejection purposes. The major geographic restriction on siting arises from avoidance of an unacceptably-high incidence of severe seismic or meteorological activity; plants sited in such areas would be subject to additional risks and would require additional-likely costly albeit eminently-feasible - engineered safeguards to protect them to the requisite reliability levels of a manifest safety environment.

As a source of baseload electricity, nuclear energy can be used to provide a large fraction of total electricity demand, e.g., as in France, which obtains nearly $80 \%$ of its electricity from nuclear reactors. By timing their refueling outages, which occur every 18 months on average, it is possible to use a fleet of nuclear plants to closely match seasonal changes in electricity demand, so that high average plant capacity factors can be maintained across an entire fleet. It is also possible to design nuclear plants that can vary their electricity production in agile manners in order to reasonably closely match daily variations in electricity demand. However, such plants would operate at an economic penalty compared to baseload plants because they would spend a smaller fraction of the time at full capacity and therefore pay for themselves less quickly. Combining "always on" nuclear plants with short-term energy storage technology (e.g., pumped storage) or some form of freely-variable energy source (e.g., geothermal or hydro generation) would allow them to supply the majority of all electricity demand at maximum economic efficiency, even as demand varies during time-of-day and -year.

Another approach for maximizing the applicability and economic efficiency of nuclear plants with a minimum of energy storage or variable energy sources is to introduce major uses of electricity that can be varied freely in time. Generally speaking, electricity demand is lowest late at night, and the highest diurnal peaking is found in summer due to air-conditioning loads, where nighttime electricity demand is on the order of $50 \%$ of the daily maximum (of course, the magnitude and seasonal-timing of these diurnal variations depends strongly on the local climate). To completely fill these nighttime load "valleys" would involve having roughly one quarter of total time-average electricity demand be of a time-insensitive nature. This is already happening to some extent with increasing electrification, e.g., charging electric ground vehicles at night. Other time-insensitive uses of electricity include many industrial processes, thermal energy storage such as making ice at night for the next day's cooling uses, and water desalination and distribution. As computing data centers spread around the globe, it 
will also be possible to distribute computational loads such that the majority of all computing is always happening at nighttime locations where electricity is locally cheap, albeit at the cost of reduced datacenter load factors.

Electricity production currently constitutes about a third of energy use in the world, and this fraction is rising as the world continues to modernize, reaching about $40 \%$ in the United States and Europe. Meanwhile, non-electrical energy is still used for a number of major applications: in land, sea, and air transportation, industry and agricultural processes, water systems and residential and commercial heating and cooling. Nuclear energy has the potential to make ever-larger inroads into all of these application-areas, both through the expanding role of electricity and by directly supplying process heat. Several of these applications are currently served by nuclear energy at small scales, including district heating, water desalination, and ship propulsion. District heating involves use of a centralized heat source to provide hot water or steam to a city or region via a large-scale piping system. Because the temperatures required are low (about $100{ }^{\circ} \mathrm{C}$ ) compared to the operating temperature of nuclear reactors, a district heating system can serve as the ultimate heat sink of a nuclear plant's power-generating thermodynamic cycle, thereby putting to good use the "waste heat" that would otherwise be lost to the environment. Examples of such systems have been implemented in Europe, such as the Beznau nuclear power plant in Switzerland, which supplies heat to roughly 15,000 residences in the region. Such heat may also be employed in "brine chillers" for air-conditioning applications, potentially on the same geographic scales as district heating ones; these may become common in the tropics over the next several decades. Nuclear electricity can also be used for efficient residential and commercial heating via heat pumps (effectively air conditioners operated in reverse), which are able to provide much more low-grade heat-energy than is electrical energy consumed by extracting heat from the outside environment.

Another important low-temperature application of nuclear heat is in water desalination using a distillation process, or in preheating water to increase the efficiency of a reverse osmosis plant. Again, such a process is able to take advantage of heat that would otherwise be wasted; the sacrifice would be a slight reduction in electricity generation efficiency due to rejecting heat at $\sim 90^{\circ} \mathrm{C}$ rather than to an ambient temperature of $\sim 30^{\circ} \mathrm{C}$. Since both nuclear heat and electricity can be used to desalinate water, there are potential synergies in having both electricity driven (reverse osmosis) and heat driven (distillation) desalination processes coexisting in a single plant adjoining a nuclear plant: for example both processes can share the same front-end and back-end infrastructure. Water desalination is poised to become a major end use of energy as a growing and denser human population requires increases amounts of adequately-pure water for both domestic and industrial uses and for agriculture, and nuclear-derived energy may be expected to play major roles both in beneficiating saline, brackish and polluted water-streams and in very large-scale pumping of these over high (gravity) heads and/or long distances.

Desalination and water distribution can offset variations in electricity demand to an excellent degree in regions without abundant and conveniently-positioned fresh water. As an example, U.S. per capita electricity consumption averages around $40 \mathrm{~kW}-\mathrm{h}$ per day, and around one-third of this- $13 \mathrm{~kW}-\mathrm{h}$ - is needed to fill in the nighttime valley in energy demand. Meanwhile, U.S. per capita fresh water consumption is around $4.5 \mathrm{~m}^{3} /$ day, which would require $\sim 10 \mathrm{~kW}$-h to produce from seawater using reverse osmosis, and an additional $\sim 3 \mathrm{~kW}$-h to pump over distances required for long-range irrigation. 
Therefore, it appears to be a fitting synergy for a nuclear reactor to supply electricity for residential and commercial use in the daytime, and then have its extra capacity at night used toward the production and distribution of fresh water.

Nuclear reactors are commonly used for ship propulsion in military applications, and have also been used on civilian ships, such as the U.S.-built NS Savannah merchant ship, and a total of ten nuclear-powered icebreaker ships of Soviet/Russian creation. Implementing nuclear reactors at the smaller scale required for general use in small and medium-sized ships may be more challenging to do economically, because the need to secure, monitor, and control these reactors to the same degree as larger ground-based nuclear installations would result in a proportionally greater overhead cost. The largest tanker and container ships, however, have power-plants in the 20-300 MWt class, and marine-diesel propulsion in aggregate currently consumes $\sim 10 \%$ of all the petroleum pumped on the planet, so that their use of nuclear power modules is not unreasonable - especially since they can be readily engineered to definitively (i.e., passively) obviate both seismic and afterheat removal issues, due to their floating nature and the ubiquitous presence of arbitrarily-great quantities of cooling water. Nuclear electricity can also play a role in smaller scale transportation via the introduction of affordable plug-in hybrids and all-electric cars, as well as in public transportation via electric buses and trains.

Finally, nuclear heat and electricity can be used for industrial processes. Since electricity can be readily converted to chemical potentials and realization of media at very high temperatures, it can be applied to processes such as the well-known alumina-reduction process for winning aluminum metal, or the use of electric arc furnaces in steelmaking. Nuclear heat and electricity can also be used to generate hydrogen, a versatile and non-polluting energy carrier. Hydrogen can be produced from nothing but water, given high temperatures $\left(\sim 650^{\circ} \mathrm{C}\right)$ and electricity (via high temperature electrolysis, which is much more electricity-efficient than electrolysis at-or-about room temperature) or given only very high temperatures $\left(\sim 850{ }^{\circ} \mathrm{C}\right.$, in the sulfur-iodine process $)$ for conducting direct thermolysis of water. These temperatures can be reached using specially-designed high temperature reactors based on ceramic materials and high temperature coolants (such as gas or liquid salt). Such specialized reactors do not necessarily need to be breeder reactors themselves; for example, they can rely on using fissile uranium-235 or plutonium-239 in the form of enriched fuel, while a primary fleet of conventional breeder reactors or TWRs is still able to extract most of the energy from the remaining uranium-238. Hydrogen produced in this way would be immediately applicable to production of ammonia for agricultural purposes (via the Haber-Bosch process, which currently consumes $\sim 2 \%$ of planetary energy and seems destined to at least double to support the estimated doubling of food-and-fiber production required by 2050), and with additional technology development could be used as a fuel for a large number of applications, including all forms of transportation. Nuclear-sourced heat, at temperatures currently attainable by sodium-cooled breeder reactors as well as other types of high temperature reactors, can also be useful as a carbon-free means of converting heavy oil (e.g., from oil shales and sands) into liquid fuels suitable for use in transportation, as well as be used for pyrolysis of biomass to produce liquid biofuels. .

Overall, nuclear reactors are already able to meet a large fraction of global energy demand by sourcing a major fraction of electricity production, which will continue to grow in importance as human civilization becomes increasingly electrified. Expanding applications for electricity and nuclear heat in the heating-and-cooling, industrial, and transportation sectors have the potential to allow 
nuclear energy systems to supply a large majority of world energy usage. Meanwhile, the transition from a fossil fuel-based energy system to one powered by nuclear fission and other renewables will also alter the basic demand profile for energy, notably by reducing the energy used in the production, refining, and transportation of fossil fuels themselves.

A key factor determining the range of applicability of any technology is its cost. For nuclear energy to be widely adopted to fill the roles described above, it must be able to do so in a cost-competitive fashion, including low economic risk. A large fraction of contemporary nuclear energy cost is due to the aggregated capital cost of building the reactor-centered power station itself, so minimizing the cost of nuclear energy may be accomplished in significant part by reducing the early costs and total elapsed time of construction of new nuclear reactors. Currently, there are examples of passively-safe light water reactors being built at what appear to be competitive costs [38], but a complete and reliable perspective on cost will only become available after a number of these modern nuclear construction projects are seen through to completion. Similarly, costs of new nuclear reactor designs such as conventional breeder reactors and TWRs will be difficult to evaluate reliably until such systems can be built at scale. Thorough implementation of manifest safety may ultimately aid significantly in achieving lower costs, since the emphasis on rigorously quantifying and validating safety performance will also reveal those safety measures which are most effective in acquiring the requisite degrees of safety at the lowest costs. Likewise, wide deployment of highly standardized designs will allow manifest safety to be more readily and pervasively achieved while also minimizing aggregate costs.

\section{Conclusions}

By concatenating uranium extraction from seawater, manifestly safe breeder reactor technology, and borehole disposal of nuclear waste, it is possible to create a nuclear energy system that is planetary-scale sustainable, i.e., one that's capable of providing such an immense amount of energy at such high power levels that it can be counted upon to fuel most—and potentially all—of human civilization throughout essentially all future scenarios of serious interest. In this regard, nuclear energy is qualitatively different from other consumable energy resources and must be objectively deemed to be fully sustainable in all respects. Furthermore, inescapable meteorological erosion continually washes uranium from mountains via rivers into the sea, thus regenerating a ubiquitous marine source of uranium that is truly renewable-moreover, at usefully large scales-in all the same senses as are hydro, wind, and solar energy.

The sustainability of such a nuclear energy system would also be characterized by its having extremely low risks of accidents, significant releases of radioactivity into the biosphere, and material diversion to weaponry-generation, with the important qualifier that the natures-and-magnitudes of these risks are known and deemed acceptable by society as a whole, in addition to being smaller than those of most-if-not-all alternatives. While resource availability is important for gauging the sustainability of a technology at very long timescales, this latter aspect of sustainability is just as critically important to the nuclear energy system of today. It can be achieved by embracing the concept of manifest safety, which entails an institutional commitment to achieving very high levels of safety and security in fashions that are entirely transparent and thus fully visible to everyone. 
With a manifestly safe nuclear energy system, nuclear heat and electricity are capable of supplying the large majority of mankind's energy needs, with nearly complete coverage becoming possible; e.g., with a nuclear-energized hydrogen economy. Such an energy system can operate indefinitely with vanishingly small relative impacts on either the natural environment or human health, because of its inherent lack of greenhouse gas emissions and the remarkably small-volume, highly-localized nature of its fuels and waste products. Waste disposal in deep boreholes - or an equivalent disposal technology - can be used to permanently isolate radioactive wastes from the biosphere until they have decayed to negligible levels of activity, while uranium extraction from seawater has an intrinsically tiny 'environmental footprint'.

Two sets of major developments are required to implement the planetary-scale sustainable nuclear energy system that we've described. The first set is technological: developing and maturing the enabling technologies of uranium extraction from seawater, manifestly safe breeder reactors, and borehole wastestream disposal. All of these technologies already have been demonstrated to the points that they appear feasible to implement at scale with reasonable cost, so the aggregated amount of technological development needed seems quite modest-and thus correspondingly low-risk - compared to implementing classic renewables or nuclear fusion energy at planetary scale. More advanced versions of these technologies will be able to further enhance safety, broaden applicability, lower costs, and open up new options: for example, continuing development of traveling wave reactors will enable a sustainable nuclear energy system that does not require either reprocessing of spent fuel or isotopic enrichment of inputted fuel.

Perhaps more important - and more challenging - than these rather straightforward technological developments is the set of institutional developments required to achieve a manifestly safe nuclear energy system. This is because manifest safety involves not only engineering effort and technological solutions to make nuclear systems safer, but also active and extended dialogues both within the nuclear energy community and with the general public about the natures and magnitudes of these risks and their addressing as a classic "commonly-owned set of issues".

Primary assurance of "good behaviors" along these lines is most naturally provided by fully-independent and highly-competent nuclear regulators resolutely committed to public interests, e.g., who are proactive in communicating their findings to the public while mandating safety in fashions which are timely and cost-efficient in conformance with widely-accepted public standards for these parameters. The independence and competence of nuclear regulators worldwide can be greatly bolstered through international cooperation and oversight, the beginnings of which can be seen in entities such as the Western European Nuclear Regulators' Association. Achieving manifest safety will also require international cooperation and openness among nuclear reactor vendors and operators so everyone can keep watch over each other, share institutional safety knowledge, financially co-insure each other's operations, and assist each other when needed, analogously to the U.S. Institute of Nuclear Power Operations albeit implemented at global scale. Finally, a trusted, well-coordinated group of monitors that continuously evaluates and publishes the state of safety of all nuclear power installations worldwide is clearly indicated as a secondary assurance of "good behaviors," so that all such safety-posture information is immediately available to anyone wishing to review it.

Establishment of an international institution to serve as a hub of international cooperation and peer monitoring on safety matters would seemingly be well suited as a goal for the International Atomic 
Energy Agency, which has an international status and overall mission that are compatible with such a task. Funding of such an institution could be provided by voluntarily participating member nuclear utilities and vendors, who could be expected to source such funding in exchange for improved public knowledge of and confidence in the safety of their nuclear facilities and their operations. Such funding can also be applied towards an accident remediation fund, which would act as an additional assurance that any negative impacts to the public caused by nuclear energy operations anywhere would be financially compensated, and that externalities would be paid-up fully, promptly and reliably.

The ability to thereby develop and demonstrate manifest safety with the current generation of new nuclear reactors likely will be essential for laying the groundwork for a sustainable future based on nuclear energy.

This paper has focused on characterizing what is achievable using nuclear energy, and so the energy system described is meant only to serve as a useful illustration, not as a proposal for how a future global energy system should or will look. Any realistic and optimal energy system will necessarily draw from a varied mix of energy sources, due to the innate regional and temporal heterogeneity of energy supplies and demands. It is also recognized that any planetary-scale energy transitions, such as significantly increasing global nuclear energy capacity, is necessarily a long and gradual process [39].

Even though this discussion on sustainability is applicable to extremely long time-frames and remarkably large power-and-energy scales, there is a comparatively-urgent component to sustainability that compels our decision-taking in the present epoch. Civilization's current reliance on fossil fuels for sourcing of primary energy is not just challenging due to long-term resource availability, but also from a relatively short-term ecosystems perspective, because our current net rate of greenhouse gas emissions into the atmosphere, if sustained through even the present century, seemingly shadows the environmental well-being of future generations over the next several centuries, until most of the resulting $\mathrm{CO}_{2}$ pulse becomes sunk into the oceans. Furthermore, these impacts are distributed across all populations around the globe, so that means to properly remediate them by "making whole" any-and-all persons that are negatively affected would be immensely difficult to put into practice.

A nuclear energy infrastructure, properly and sustainably implemented, is one of relatively few options which are reasonably-and-reliably accessible that can potentially address these significant, comparatively near-term challenges. Therefore, it seems important that we as creators and dependents of a global civilization begin to lay the technical and institutional groundwork that will enable a sustainable, full-scale nuclear energy system to become an operational reality in the reasonably near term, while concurrently doing likewise for other practical forms of sustainable energy supply at-scale.

\section{Acknowledgments}

We are grateful to our many TerraPower colleagues for their collaboration on several of the topics surveyed in this paper, to TerraPower's leadership for especially enlightened and forward-looking guidance, and to Bill Gates for his visionary inspiration and generous support of these and many other energy-related efforts.

\section{Conflict of Interest}

The authors declare no conflict of interest. 


\section{References and Notes}

1. U.S. Energy Information Administration. Annual Energy Outlook 2012; DOE/EIA-0383(2012); U.S. Energy Information Administration: Washington, DC, USA, 2012. Available online: http://www.eia.gov/forecasts/aeo/pdf/0383(2012).pdf (accessed on 30 October 2012).

2. ExxonMobil. 2012 The Outlook for Energy: A View to 2040, 2012. Available online: http://www.exxonmobil.com/energyoutlook (accessed on 30 October 2012).

3. International Atomic Energy Agency. Nuclear Power Reactors in the World, Reference Data Series No.2, 2012 Edition; IAEA-RDS-2/32; IAEA: Vienna, Austria, 2012. Available online: http://www-pub.iaea.org/MTCD/Publications/PDF/RDS2-32_web.pdf (accessed on 30 October 2012).

4. U.S. Energy Information Administration. Monthly Energy Review, April 2012; Office of Energy Statistics, U.S. Department of Energy: Washington, DC, USA, 2012.

5. Kardashev, N.S. Transmission of information by extraterrestrial civilizations. Sov. Astron. 1964, 8, 217.

6. U.S. Geological Survey. World Petroleum Assessment 2000. Available online: http://pubs.usgs.gov/dds/dds-060/ (accessed on 30 October 2012).

7. Alboudwarej, H.; Felix, J.; Taylor, S.; Badry, R.; Bremner, C.; Brough, B.; Skeates, C.; Baker, A.; Palmer, D.; Pattison, K.; et al. Highlighting Heavy Oil, Oilfield Review. Available online: http://www.slb.com/ /media/Files/resources/oilfield_review/ors06/sum06/heavy_oil.pdf (accessed on 30 October 2012).

8. U.S. Energy Information Administration. EIA International Energy Statistics: Coal: Recoverable Reserves, 2012. Available online: http://www.eia.gov/cfapps/ipdbproject/IEDIndex3.cfm?tid= $1 \&$ pid $=7 \&$ aid $=6$ (accessed on 30 October 2012).

9. Milkov, A.V. Global estimates of hydrate-bound gas in marine sediments: How much is really out there? Earth Sci. Rev. 2004, 66, 183-197.

10. Olipitz, W.; Wiktor-Brown, D.; Shuga, J.; Pang, B.; McFaline, J.; Lonkar, P.; Thomas, A.; Mutamba, J.T.; Greenberger, J.S.; Samson, L.D.; et al. Integrated molecular analysis indicates undetectable DNA damage in mice after continuous irradiation at $\sim 400$-fold natural background radiation. Environ. Health Perspect. 2012, 8, 1130-1136.

11. Burgherr, P.; Hirschberg, S. A comparative analysis of accident risks in fossil, hydro and nuclear energy chains. Hum. Ecol. Risk Assess. 2008, 14, 947-973.

12. Hirschberg, S.; Spiekerman, G.; Dones, R. Severe Accidents in the Energy Sector; PSI Bericht Nr. 98-16; Paul Scherrer Institut: Villigen, Switzerland, 1998.

13. Findlay, T.; Nuclear Energy and Global Governance: Ensuring Safety, Security and Non-proliferation; Routledge: Oxon, UK, 2012.

14. Ku, T.L.; Knauss, K.G.; Mathieu, G. Uranium in open ocean: Concentration and isotopic composition. Deep Sea Res. 1977, 24, 1005-1017.

15. Tamada, M.; Seko, N.; Kasai, N.; Shimizu, T. Cost Estimation of uranium recovery from seawater with system of braid type adsorbent. Trans. Atom. Energ. Soc. Jpn. 2006, 5, 358-363.

16. Westinghouse Electric Company. AP1000 Design Control Document; APP-GWGL-700, Revision 18; Westinghouse Electric Company: Cranberry, PA, USA, 2010. 
17. Ott, K.O. Inherent shutdown capabilities of metal-fueled liquid-metal-cooled reactors during unscrammed loss-of-flow and loss-of-heat-sink incidents. Nucl. Sci. Eng. 1988, 99, 13-27.

18. Sakai, T.; Takeda, T.; Soraoka, H.; Yanagisawa, K. Development of a Probabilistic Tsunami Hazard Analysis in Japan. In Proceedings of ICONE 14, International Conference on Nuclear Engineering, Miami, FL, USA, 17-20 July 2006.

19. Epstein, W. A Probabilistic Risk Assessment Practitioner Looks at the Great East Japan Earthquake and Tsunami; Research Paper; Tokyo Institute of Technology, Ninokata Laboratory white paper: Tokyo, Japan, 2011.

20. Teller, E.; Hyde, R.; Ishikawa, M.; Nuckolls, J.; Wood, L. Completely Automated Nuclear Reactors for Long-Term Operation II. In Proceeding of ICENES'96, International Conference on Emerging Nuclear Energy Systems, Obninsk, Russia, 24-28 June 1996.

21. Ellis, T.; Petroski, R.; Hejzlar, P.; Zimmerman, G.; McAlees, D.; Whitmer, C.; Touran, N.; Hejzlar, J.; Weaver, K.; Walter, J.; et al. Traveling-Wave Reactors: A Truly Sustainable and Full-Scale Resource for Global Energy Needs. Presented on the International Congress on Advances in Nuclear Power Plants 2010, ICAPP, San Diego, CA, USA, 2010; pp. 546-558.

22. Petroski, R. Direct use of depleted uranium as fuel in a traveling wave reactor. Trans. Am. Nucl. Soc. 2009, 101, 741-742.

23. Touran, N.; Hejzlar, P.; Mazurkiewicz, S.; Petroski, R.; Walter, J.; Whitmer, C. Technical considerations and capabilities of a near-term deployable traveling wave reactor core. Trans. Am. Nucl. Soc. 2011, 104, 934-936.

24. Petroski, R.; Cheatham, J.; Hejzlar, P.; Povirk, G.; Schloss, P.; Whitmer, C. Traveling wave reactor core design using massively parallel precomputation. Trans. Am. Nucl. Soc. 2012, 106, 830-833.

25. Sekimoto, H.; Ryu, K.; Yoshimura, Y. CANDLE: The New Burnup Strategy. Nucl. Sci. Eng. 2001, 139, 306-317.

26. Petroski, R.; Forget, B.; Forsberg, C. Characterizing limited separations fuel cycles using breed-and-burn reactors. Nucl. Tech. 2012, 180, 28-45.

27. Brady, P.V.; Arnold, B.W.; Freeze, G.A.; Swift, P.N.; Bauer, S.J.; Kanney, J.L.; Rechard, R.P.; Stein, J.S. Deep Borehole Disposal of High-Level Radioactive Waste; Sandia report SAND20094401; Sandia National Laboratories: Albuquerque, NM, USA, 2009.

28. Arnold, B.W.; Brady, P.V.; Bauer, S.J.; Herrick, C.; Pye, S.; Finger, J. Reference Design and Operations for Borehole Disposal of High-Level Radioactive Waste; Sandia Report SAND2011-6749; Sandia National Laboratories: Albuquerque, NM, USA, 2011.

29. Driscoll, M.J.; Lester, R.K.; Jensen, K.G.; Arnold, B.W.; Swift, P.N.; Brady, P.V. Technology and Policy Aspects of Deep Borehole Nuclear Waste Disposal. Nucl. Tech. 2012, 180, 111-121.

30. World Nuclear Association. World Nuclear Power Reactors \& Uranium Requirements. Available online: http://www.world-nuclear.org/info/reactors.html (accessed on 15 July 2012).

31. Ackerman, J.P.; Johnson, T.R.; Chow, L.S.H.; Carls, E.L.; Hannum, W.H.; Laidler, J.J. Treatment of wastes in the IFR fuel cycle. Progr. Nucl. Energ. 1997, 31, 141-154.

32. Cohen, B. Breeder reactors: A renewable energy source. Am. J. Phys. 1983, 51, 75-76. 
33. Sarin, M.M.; Krishnaswami, S.; Somayajulu, B.L.K.; Moore, W.S. Chemistry of uranium, thorium, and radium isotopes in the Ganga-Brahmaputra river system: Weathering processes and fluxes to the bay of Bengal. Geochim. Cosmochim. Acta 1990, 54, 1387-1396.

34. Serchuck, A. The Environmental Imperative for Renewable Energy: An update; Renewable Energy Policy Project: Washington, USA, April 2000.

35. Sovacool, B.K. Valuing the greenhouse gas emissions from nuclear power: A critical survey. Energ. Pol. 2008, 36, 2940-2953.

36. General Electric. PRISM Preliminary Safety Information Document; GEFR-00793; General Electric: San Jose, CA, USA, 1987.

37. International Energy Agency. Electricity/Heat in World in 2009. Available online: http://www.iea.org/stats/electricitydata.asp?COUNTRY_CODE=29 (accessed on 15 July 2012).

38. Bloomberg News. Nuclear Boom In China Sees Reactor Builders Risk Their Know-how For Cash. Available online: http:/www.bloomberg.com/news/2010-12-02/china-nuclear-boom-seesreactor-builders-risk-know-how-for-cash.html (accessed on 15 July 2012).

39. Smil, V. Energy Myths and Realities: Bringing Science to the Energy Policy Debate; In The Pace of Energy Transitions; AEI Press: Washington, DC, USA, 2010.

(C) 2012 by the authors; licensee MDPI, Basel, Switzerland. This article is an open access article distributed under the terms and conditions of the Creative Commons Attribution license (http://creativecommons.org/licenses/by/3.0/). 